\title{
OS MULTIPLICADORES DE EMPREGO E RENDA DA INDÚSTRIA DE PAPEL E CELULOSE NO ESTADO DO PARANÁ - 1998 \\ UMA APLICAÇÃO DA MATRIZ DE CONTABILIDADE SOCIAL
}

\author{
Blás Enrique Caballero Nuñez ${ }^{1}$ \\ Ricardo Kureski ${ }^{2}$ \\ Carlos Henrique Passos Pacheco ${ }^{3}$
}

\section{INTRODUÇÃO}

O Brasil passou por planos econômicos de estabilização na década de 1990 que tiveram como ponto positivo a redução das taxas de inflação e como ponto negativo o aumento das taxas de desemprego. O Plano Collor, em março de 1990, adotou política de retração da atividade econômica. Foram adotadas as seguintes medidas: promoção da reforma monetária, bloqueio da maior parte dos ativos financeiros, congelamento temporário dos preços e salários e reajuste das tarifas públicas, implementação das privatizações, abertura comercial e adoção do sistema flexível de câmbio. Essas medidas fizeram com que o PIB tivesse queda de 4,3\% em 1990, refletindo na queda do nível de emprego. A inflação fechou em 11,3\% em abril de 1990 (FURTADO, p. 231). Entretanto, em janeiro de 1991, com a volta do processo inflacionário, o Governo Collor, com um novo pacote econômico, o Plano Collor II, congelou preços e salários.

${ }^{1}$ Doutor em Economia (USP). Professor do Programa de Pós-Graduação em Economia e Política Florestal da UFPR. blas@ufpr.br

${ }^{2}$ Doutor em Economia e Política Florestal (UFPR). Professor da Pontifícia Universidade Católica do Paraná. Pesquisador do Ipardes. kureski@pr.gov.br.

${ }^{3}$ Doutor em Economia e Política Florestal (UFPR). Professor da Pontifícia Universidade Católica do Paraná.idea@ideaconsult.com.br 
Com o impeachment de Collor, assume Itamar Franco, que em 14 de julho de 1993 faz a implementação do Programa de Ação Imediata (PAI), aplicando corte nos gastos públicos, aceleração e ampliação do processo de privatização, saneamento do sistema bancário; proposta de um novo sistema fiscal e tributário ao Congresso, estabelecimento de uma política cambial em que a desvalorização da moeda nacional acompanhasse a variação da inflação, e prosseguimento do processo de abertura comercial. Esse Programa foi preparação para o Plano Real, implementado em 27 de março de 1994, com a criação da Unidade de Referência de Valor (URV), corrigida diariamente, que passou a referenciar os preços e salários. A partir de $1 .^{\circ}$ de julho, foi adotado o real como moeda corrente. Com relação à política cambial, adotouse o sistema de "bandas", em que o real podia variar dentro de limites estabelecidos pelo Banco Central. O resultado foi a redução da taxa de inflação (LACERDA, p. 207; FURTADO, p. 225).

Com a valorização do real e a abertura da economia, as empresas tiveram de se adaptar à concorrência externa. Assim, segundo Lanzana (1998, p. 499), as empresas tomaram medidas para enfrentar a concorrência de produtos importados, tais como: restruturação do método de produção, terceirização de parte das atividades, maior racionalização dos métodos de trabalho, busca de qualidade e redefinição de linhas de produção. Estas medidas repercutiram no mercado de trabalho com a redução do emprego por unidade de produto, restruturação do emprego na economia e redução do poder da ação dos sindicatos.

Então, a redução das taxas inflacionais, outra questão macroeconômica, surgiu com ênfase no cenário econômico brasileiro, resultando no desemprego. Essa questão é descrita da seguinte forma:

No Brasil, o termo emprego não chegou a ter, até recentemente, com exceção da crise do início dos anos 80 , peso muito grande em termos políticos e influência na agenda de preocupações da população em geral, como a que exerce nos países industrializados e, mais recentemente, na Argentina. A explicação é simples e reside na dimensão da variável. Com taxas de desemprego de $4 \%$ a $5 \%$, muitos argumentavam que o Brasil não tinha um "problema" de desemprego, e sim de "qualidade" de emprego, ligado à precariedade que marca parte expressiva dos postos de trabalho. Entretanto, com taxas de desemprego de $7 \%$ ou mais, é compreensível que tenha aumentado o contigente daqueles que entende que o Brasil passou a ter, também, um problema de desemprego elevado (REIS, 1998, p. 67). 
Segundo Chahad (1998, p. 256), ocorreu uma mudança no emprego formal, resultante principalmente do Setor Industrial. Isso decorreu dos novos padrões tecnológicos, organizacionais e gerenciais. Assim, houve uma mudança na relação capital-trabalho, sendo necessário um volume maior de capital para gerar um novo emprego. Faz-se também a necessidade da contratação de trabalhadores com maior qualificação, aumentando a produtividade, obtendo vantagens na globalização. A manutenção da estabilidade de preços por meio de um câmbio valorizado e a ineficiência da infra-estrutura produtiva do país dificultaram a geração de novos empregos.

Um método para planejar a política governamental de redução do desemprego é a utilização da matriz de insumo-produto, que apresenta as relações entre os diversos setores da economia. É utilizado para estimar as variações nos níveis de produção setorial resultantes das variações nos níveis de demanda final, que é determinada exogenamente. Utilizando os multiplicadores diretos e indiretos da matriz, é possível determinar o efeito do aumento da demanda final na geração de emprego. Entretanto, quando ocorre aumento de produção, altera-se o valor adicionado e, conseqüentemente, a renda. Como a renda influencia o consumo, esse incremento de renda gerará novos impactos sobre a produção. Assim, tornando a consumo das famílias uma variável endógena, é possível medir os efeitos do incremento da renda na geração de novos empregos.

Outro instrumento de análise da geração de empregos é a matriz de contabilidade social. Como descreve Forchezatto (2001), a matriz de contabilidade social é importante instrumento de análise econômica, pois demonstra a interdependência entre os diversos agentes e mercados. Ela abrange o total dos fluxos de renda da economia e as transações entre todos os agentes econômicos, organizadas de maneira consistente, de modo a igualarem-se receitas e despesas de cada agente. A matriz de contabilidade social, ao contrário da matriz de insumo-produto, informa a renda gerada pelos fatores de produção das atividades econômicas e apropriada pelas famílias, que são as unidades econômicas relevantes para a decisão de consumo final (SAMPAIO, 2000).

O objetivo deste trabalho é determinar os multiplicadores de emprego e renda direto, indireto e induzido da economia paranaense, dando ênfase para a Indústria de Papel e Celulose e Madeira e Mobiliário para o ano de 2004. O método empregado para obter os multiplicadores foi a matriz de contabilidade social (MCS). 


\section{ESTRUTURA DA MATRIZ DE CONTABILIDADE SOCIAL}

A MCS é um sistema de dados com a mesma tabulação, desagregado, consistente e completo, que captura as interdependências que existem no sistema socioeconômico. Conforme sua desagregação, pode ser utilizada para determinar os setores-chave da economia, os fluxos inter-regionais da região ou Estado, a distribuição de renda entre os grupos socioeconômicos, além da estrutura e da tecnologia da produção e dos recursos obtidos pelos grupos. Pode ser utilizada para calcular os impactos exógenos que resultam das exportações, dos gastos do governo e dos investimentos (THORBECKE, p. 280).

O Quadro 1 apresenta uma MCS básica, na qual pode ser prontamente vista a incorporação de todas as transações importantes dentro de um sistema socioeconômico. Uma MCS é uma matriz quadrada em que cada conta tem sua própria linha e coluna. As saídas são listadas em colunas, e as entradas são registradas em linha. Como a soma de todas as despesas por uma conta deve ser igual à soma total dos pagamentos para a conta correspondente, a soma da linha deve ser igual à soma de coluna da conta correspondente. Por exemplo, o pagamento total para a conta das famílias deve ser igual às despesas totais delas.

Na MCS básica do Quadro 1, seis contas são distintas. A conta atividade produz bens e serviços de diferentes setores (por exemplo, o de Produtos Têxteis), que compram insumos e serviços intermediários da própria região, de outros estados e de outros países. Além disso, pagam impostos e renda para os fatores de produção.

$\mathrm{Na}$ formulação da MCS, não é feita nenhuma distinção entre atividades e produto. Por causa da simplicidade, é admitido que uma conta atividade é equivalente para um correspondente a produto. Em algumas instâncias, o formato da MCS distingue entre atividade e produto. Isso ocorre quando uma atividade gera produtos diferentes, o que exige um conjunto de contas diferentes (THORBECKE, p. 288).

Os fatores de produção considerados incluem tipicamente trabalho e capital. Eles recebem renda (valor adicionado, registrado na linha 2) pela utilização dos fatores da conta atividade na forma de salário, lucro bruto e de renda recebida do mundo e do país. Por sua vez, estas rendas (coluna 2) são distribuídas para as famílias como rendas de trabalho e para as empresa como lucros.

As instituições incluem famílias (divididas entre grupos socioeconômicos), empresas e o governo. Na linha 3a, observa-se que as famílias recebem renda de fator de produção trabalho, ou seja, dos salários, e dos 
fatores de produção terra e capital, na forma de aluguel e lucro distribuídos aos empregados. Outra forma de recebimento de renda das famílias são transferências do governo e do restante do país e do mundo (por exemplo, remessas de salários). As despesas das famílias (coluna 3a) consistem em consumo em bens da região, de outras regiões, do exterior e imposto de renda. A diferença entre a renda e o consumo é a poupança, que é transferida para a conta de capital. As empresas (3b) recebem lucros e subsídios e gastam em impostos e transferências. O lucro retido vai para sua conta de capital.

A conta do governo (linha 4) compra bens e serviços intermediários da conta atividade e paga salários. A soma dos gastos com o consumo intermediário e salários e o valor do consumo do governo é o valor total de bens públicos fornecidos à sociedade. Outras despesas do governo (col. 4) são transferências e subsídios para famílias e empresas, e a poupança restante do governo é transferida para a conta de capital. No lado de receita, o governo recebe impostos diretos e indiretos, imposto sobre a empresa e sobre a FBKF.

$\mathrm{Na}$ linha 5 está a conta de capital, na qual as entradas são compostas pela poupança de famílias, empresas e governo, como também pela poupança do restante do país e do mundo. A poupança é canalizada para a Formação Bruta de Capital Fixo (FBKF), que visa a aumentar a capacidade produtiva do Estado ou região (coluna 5).

$\mathrm{Na}$ linha 6 estão as transações entre residentes e não-residentes, respectivamente, registradas nas contas do restante do país e do mundo. Essas transações incluem, no lado de recebimento, despesas de consumo das famílias em importação de bens finais, como também importações de bens de capital e matérias-primas pelas empresas (linha 6a e 6b). A economia recebe renda do restante do país e do mundo (coluna 6), exportações de bens finais e intermediários e financiamentos.

\section{Multiplicadores da matriz de contabilidade social}

Quando existe excesso dos fatores de produção, tais como trabalhadores desempregados, por meio dos multiplicadores contábeis da MCS é possível estimar o efeito de uma mudança das variáveis exógenas. Como mudança das variáveis exógenas entende-se um aumento das exportações ou dos investimentos ou aumento dos gastos do governo. O incremento nas variáveis endógenas gera aumento da produção sem ter efeito nos preços.

O total dos efeitos diretos e indiretos, resultante de uma injeção direcionada nas contas endógenas sobre a produção das empresas, sobre a 
remuneração dos fatores de produção e a renda das famílias, é estimado por meio dos multiplicadores da MCS.

Thorbecke (1998) mostra como o efeito multiplicador se propaga na economia. Por exemplo, um estudo público de viabilidade de uma fazenda verificou a necessidade da construção de uma estrada para comercialização dos produtos. A construção da estrada vai demandar trabalhadores inexperientes como os trabalhadores rurais (bóias-frias) e os pequenos proprietários rurais. Esses dois grupos socioeconômicos de trabalhadores terão a renda aumentada e, conseqüentemente, aumentarão sua demanda por alimentos. $\mathrm{O}$ aumento subseqüente em produção de comida leva à necessidade de emprego ainda adicional e incrementos de renda para estes grupos, e assim por diante, até que o processo multiplicador amorteça. 
NUÑEZ, B. E. C.; KURESKI, R.; PACHECO, C. H. P. Os multiplicadores de emprego e renda...

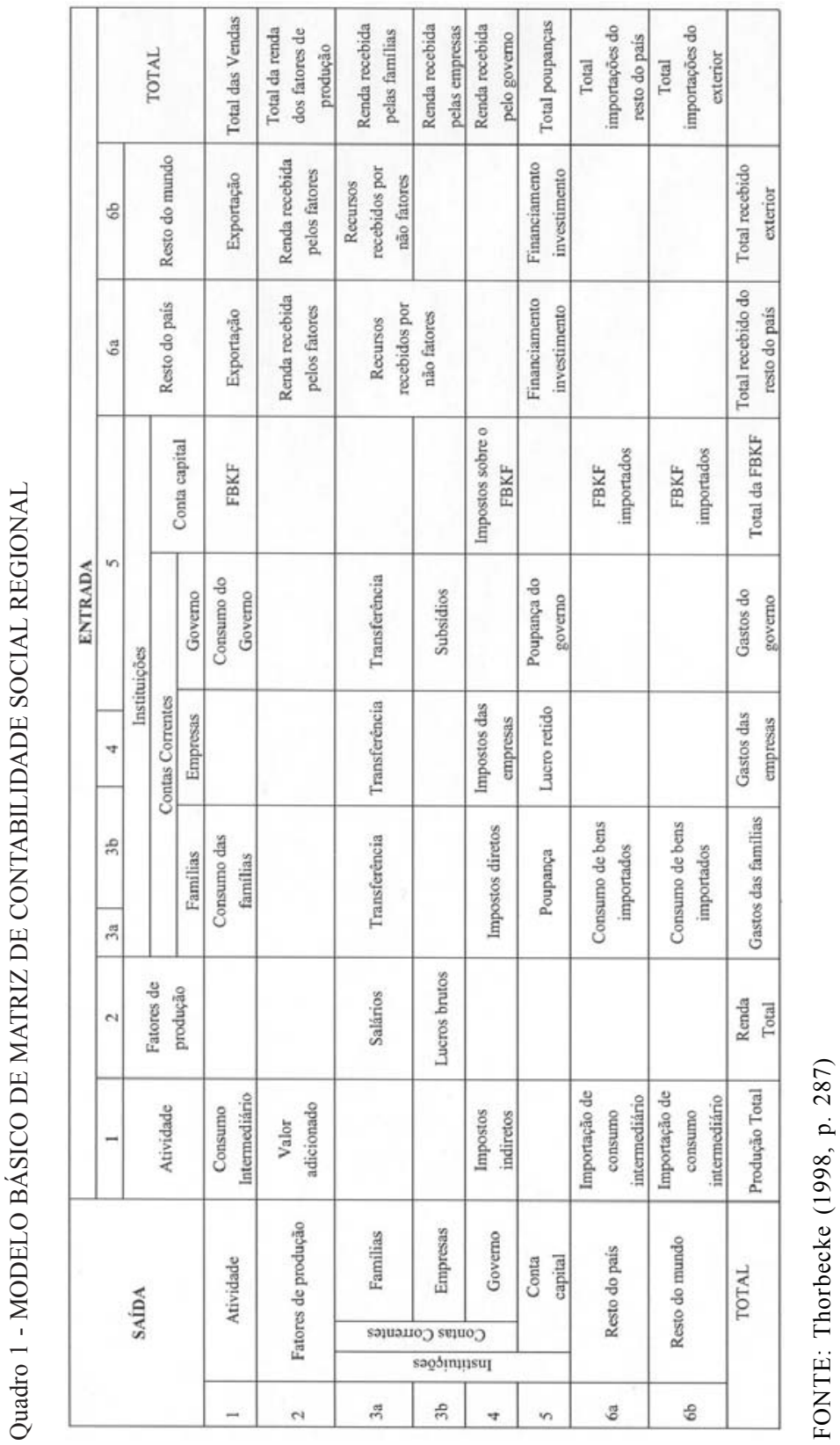


O Quadro 2 apresenta uma MCS simplificada, com três contas endógenas (Atividades, Fatores e Instituições) e uma conta exógena. As três contas exógenas foram combinadas juntas. As injeções referentes ao aumento do dispêndio do governo, do investimento e das exportações, respectivamente, são consolidadas em três vetores: $\mathrm{f}_{1}, \mathrm{f}_{2}, \mathrm{f}_{3}$.

O primeiro vetor $\left(f_{1}\right)$ representa o total dos exógenos da demanda para as atividades de produção, resultante de consumo do governo, demanda de investimento e exportação. De forma semelhante, $\mathrm{f}_{2}$ e $\mathrm{f}_{3}$ representam, respectivamente, o total exógeno da demanda para fatores (e conseqüentemente injeção de renda para recompensar fatores) e total de renda exógeno, resultante para diferentes instituições, como subsídios do governo e remessas para o exterior. Igualmente, $\mathbf{f}_{\mathbf{i}}$ corresponde a importações, poupança e tributação.

A lógica do esquema do Quadro 2 demonstra que uma mudança nas contas exógenas (o $\mathrm{f}_{\mathrm{i}}$ 's) determina, mediante sua interação dentro da matriz de MCS, os fluxos do consumo intermediário, da renda e do consumo das famílias das contas endógenas. $\mathrm{O}$ valor da produção corresponde ao vetor $\mathrm{y} 1$, a renda dos fatores corresponde ao vetor $\mathrm{y} 2$, e a renda das instituições, ao vetor y3.

Definindo-se como $\mathbf{T}$ a matriz de transações do MCS, em que tij corresponde ao pagamento da conta coluna j para conta linha i. A matriz de coeficientes técnicos diretos da MCS é construída a partir da matriz T, dividindo cada célula de cada coluna de $\mathbf{T}$ pelo somatório da coluna: 
NUÑEZ, B. E. C.; KURESKI, R.; PACHECO, C. H. P. Os multiplicadores de emprego e renda...

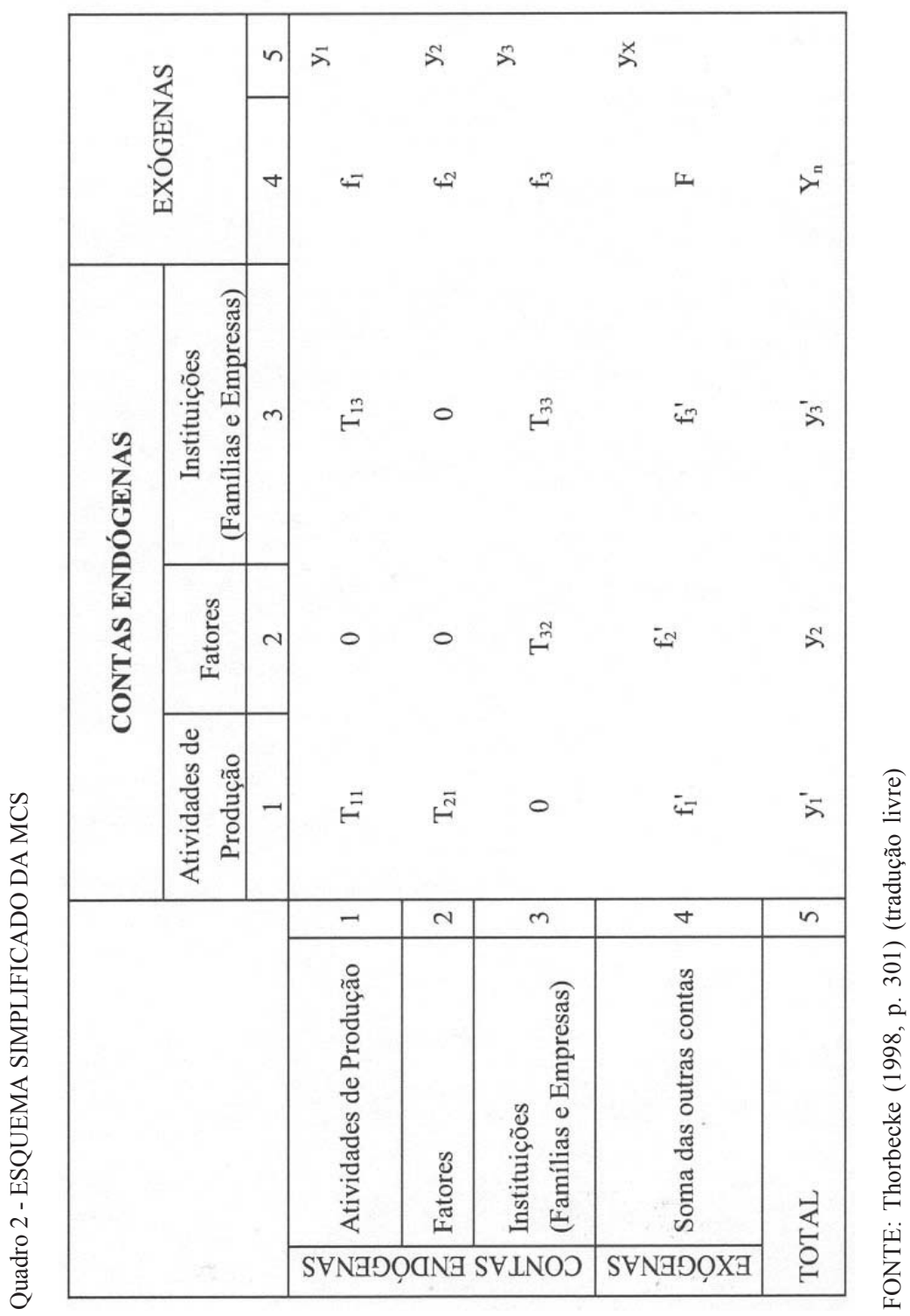


A matriz dos coeficientes técnicos diretos é representada da seguinte forma na estrutura matricial:

$$
A n=\left[\begin{array}{ccc}
A 11 & 0 & A 13 \\
A 21 & 0 & 0 \\
0 & A 32 & A 33
\end{array}\right]
$$

Descrevendo cada conjunto de matriz que compõe a matriz An, tem-se:

a) o subconjunto $A_{11}$, que é o conjunto de coeficientes de produção. Corresponde ao valor do aumento do fornecimento de insumo pelo aumento de uma unidade monetária nas variáveis exógenas;

b) o subconjunto $A_{21}$, que é o conjunto de coeficientes técnicos dos valores adicionados. Corresponde ao valor adicionado pelo aumento de uma unidade monetária nas variáveis exógenas;

c) os coeficientes do subconjunto $A_{13}$, que mostram a participação de cada atividade na composição das compras de grupo domésticas nas despesas totais;

d) os coeficientes do subconjunto $A_{33}$, que mostram as transferências de renda para outros grupos domésticos por unidade monetária de renda;

e) os coeficientes do subconjunto $A_{32}$, que demonstram a participação das famílias, empresas e dos impostos na renda gerada.

No Quadro 2, conforme se observa na matriz, o total da renda $\left(\mathrm{Y}_{\mathrm{n}}\right)$ é dado pela seguinte fórmula:

$$
\mathrm{Yn}=\mathrm{An} \mathrm{Yn}+\mathrm{f}
$$

A equação 2.1.3 pode ser reescrita como:

$$
\mathrm{Yn}=(\mathrm{I}-\mathrm{An})^{-1} \mathrm{f}
$$

Em que:

$\mathrm{Yn}=$ Valor das rendas

$\mathrm{I}=$ Matriz identidade

An $=$ Coeficiente técnico direto

$(\mathrm{I}-\mathrm{An})^{-1}=$ Matriz dos multiplicadores contábeis

$\mathrm{f}=$ Somatório das variáveis exógenas.

$\mathrm{Na}$ equação (2.1.4), $\mathrm{Y}_{\mathrm{n}}$ pode ser dividido em $\mathrm{Y}_{1}$, que corresponde à produção total de bens e serviços; $\mathrm{Y}_{2}$, que demostra o total do valor adicionado distribuído entre os fatores de produção; e $\mathrm{Y}_{3}$, que corresponde ao total da renda apropriada pelas instituições. Assim, pode-se reescrever a equação (2.1.3) de forma desagregada: 


$$
\begin{array}{llll}
Y_{1}=A_{11} Y_{1} & & +A_{13} Y_{2} & +f_{1} \\
Y_{2}=A_{21} Y_{1} & & & +f_{2} \\
Y_{3}= & A_{32} Y_{2}+A_{33} Y_{3} & +f_{3}
\end{array}
$$

Reescrevendo a fórmula (2.1.5), tem-se:

$$
\begin{array}{llll}
Y_{1}= & & \left(I-A_{11}\right)^{-1} A_{13} Y_{3} & +\left(I-A_{11}\right)^{-1} f_{1} \\
Y_{2}=A_{21} Y_{1} & & & +f_{2} \\
Y_{3}= & & & +\left(I-A_{33}\right)^{-1} f_{3}
\end{array}
$$

Uma injeção por meio do aumento das exportações, do gasto do governo ou investimento $\left(f_{1}\right)$ resulta em um aumento adicional da produção em $\left(\mathrm{I}-\mathrm{A}_{11}\right)^{-1} \mathrm{f}_{1}$. Também é necessário o emprego de novos fatores de produção, ocasionando o incremento do valor adicionado $\left(\mathrm{A}_{21} \mathrm{f}_{1}\right)$, mais fatores exógenos recebidos de outras regiões ou países ou do governo, denomina$\operatorname{dos} \mathrm{f}_{2}$. Então:

$$
Y_{2}=A_{21} Y_{1}+f_{2}
$$

Em seguida, as instituições recebem renda $\left(\mathrm{I}-\mathrm{A}_{33}\right)^{-1} \mathrm{~A}_{32} \mathrm{Y}_{2}$ com base na propriedade dos fatores de produção. Ocorre a transferência entre as instituições, como subsídio do governo $\left(\mathrm{I}-\mathrm{A}_{33}\right)^{-1} \mathrm{f}_{3}$. Então:

$$
Y_{3}=\left(I-A_{33}\right)^{-1} A_{32} y_{2}+\left(I-A_{33}\right)^{-1} f_{3}
$$

Finalizando, fecha-se o triângulo, as instituições aumentam sua demanda, resultando em $\mathbf{n}$ produção de novos produtos, graças ao incremento da renda. Esse fluxo é representado pela seguinte fórmula:

$$
Y_{1}=\left(I-A_{11}\right)^{-1}\left(A_{13} y_{3}+f_{3}\right)
$$

Os multiplicadores do MCS (I-An) ${ }^{-1}$ diferem dos multiplicadores de Leontief ( $\left(\mathrm{I}-\mathrm{A}_{11}\right)^{-1}$ pelo fato de os primeiros incluírem a renda dos fatores de produção e o nível de renda, e, em última instância, o padrão de despesas resultante aberto em produto ou atividade gera multiplicadores mais amplos, se comparados com os multiplicadores de Leontief, que são mais limitados.

\section{OS MULTIPLICADORES DE EMPREGO E RENDA}

Na seção anterior apresentou-se a estrutura da MCS e os procedimentos para obtenção dos multiplicadores da MCS, em que a conta de salário encontra-se agregada. A estrutura da Matriz de Contabilidade Social pode 
variar de acordo com as necessidades dos estudos para os quais está sendo utilizada. Assim sendo, abriu-se a conta Trabalho em quatro subcontas: empregado com carteira, empregado sem carteira, conta própria e empregador.

Para obter essa nova abertura, utilizaram-se dados da Pesquisa Nacional de Amostra Domiciliar (Pnad) do Instituto Brasileiro de Geografia e Estatística (IBGE). Entretanto, a agregação da Pnad difere da agregação da MCS do Paraná. Esse problema de compatibilização e agregação também foi enfrentado por Moreira (1994). No Brasil, as estatísticas demográficas (Pnad) e as estatísticas referentes à produção (Matriz de Relações Intersetoriais) não possuem a mesma classificação, sendo necessária a construção de tradutor para sua compatibilização. Os trabalhos que necessitam de dados demográficos e de produção geralmente são realizados de forma mais agregada, como é o caso da Matriz de Contabilidade Social. A primeira matriz apresentada é de 49 x 49, não havendo nenhuma abertura nas contas das instituições. Como a Matriz de Contabilidade Social viabiliza o estudo de determinadas instituições de forma desagregada, por meio de uma tabulação especial da Pnad, desmembrou-se a conta do trabalho em quatro subcontas:

a) empregado com carteira: pessoa que trabalhava para um empregador (pessoa física ou jurídica), geralmente obrigando-se ao cumprimento de uma jornada de trabalho e recebendo, em contrapartida, uma remuneração em dinheiro, mercadorias, produtos ou benefícios (moradia, comida, roupas, etc.), com registro na carteira de trabalho, incluindo militares e funcionários públicos estatutários;

b) empregado sem carteira: pessoa que trabalhava para um empregador (pessoa física ou jurídica), geralmente obrigando-se ao cumprimento de uma jornada de trabalho e recebendo, em contrapartida, uma remuneração em dinheiro, mercadorias, produtos ou benefícios (moradia, comida, roupas, etc.), sem registro na carteira de trabalho;

c) conta própria: pessoa que trabalhava explorando o seu próprio empreendimento, sozinha ou com sócio, sem ter empregado e contando ou não com a ajuda de trabalhador não remunerado;

d) empregador: pessoa que trabalhava explorando o seu próprio empreendimento, com pelo menos um empregado.

A Tabela 1 apresenta os dados da Pnad referentes ao pessoal ocupado no Paraná. Em 1998, o Estado possuía 3,724 milhões de pessoas ocupadas, sendo $38,7 \%$ empregados com carteira, 31,8\% empregados sem carteira, $24,2 \%$ conta própria e 5,3\% empregadores. A atividade Serviço se destaca como principal empregadora, com 939 mil empregados $(25,21 \%$ do pessoal ocupado), sendo constituída, na sua maioria, por pessoas que tra- 
balham por conta própria (cerca de 41,22\%). Nas segunda e terceira colocações vêm a Agropecuária e o Comércio, com $16,42 \%$ e $15,76 \%$ do pessoal ocupado, respectivamente.

Tabela 1 - PESSOAL OCUPADO, SEGUNDO A ATIVIDADE, NO PARANÁ - 1998

\begin{tabular}{|c|c|c|c|c|c|c|c|c|c|c|c|}
\hline \multirow{2}{*}{\multicolumn{2}{|c|}{ ATIVIDADE }} & \multicolumn{2}{|c|}{ TOTAL } & \multicolumn{2}{|c|}{\begin{tabular}{c|} 
EMPREGADOS \\
COM CARTEIRA \\
\end{tabular}} & \multicolumn{2}{|c|}{$\begin{array}{c}\text { EMPREGADOS } \\
\text { SEM CARTEIRA } \\
\end{array}$} & \multicolumn{2}{|c|}{$\begin{array}{c}\text { CONTA } \\
\text { PRÓPRIA } \\
\end{array}$} & \multicolumn{2}{|c|}{ EMPREGADOR } \\
\hline & & Abs. & $\%$ & Abs. & $\%$ & Abs. & $\%$ & Abs. & $\%$ & Abs. & $\%$ \\
\hline 1 & Agropecuária & 611641 & 16,42 & 108258 & 7,50 & 216999 & 18,30 & 262594 & 29,16 & 23790 & 12,17 \\
\hline 2 & Extrativa mineral & 4571 & 0,12 & 3427 & 0,24 & 524 & 0,04 & - & - & 620 & 0,32 \\
\hline 3 & Minerais não-metálicos & 23805 & 0,64 & 15188 & 1,05 & 5809 & 0,49 & 523 & 0,06 & 2285 & 1,17 \\
\hline 4 & Siderurgia & 51591 & 1,39 & 34228 & 2,37 & 9167 & 0,77 & 1763 & 0,20 & 6433 & 3,29 \\
\hline 5 & Máquinas e tratores & 23807 & 0,64 & 18780 & 1,30 & 2906 & 0,25 & - & - & 2121 & 1,09 \\
\hline 6 & Metalurgia & 24101 & 0,65 & 23056 & 1,60 & 784 & 0,07 & - & - & 261 & 0,13 \\
\hline 7 & Mat. elétrico e equip. elet. & 12051 & 0,32 & 11268 & 0,78 & 783 & 0,07 & - & - & - & - \\
\hline 8 & Madeira e mobiliário & 115465 & 3,10 & 69869 & 4,84 & 24541 & 2,07 & 16389 & 1,82 & 4666 & 2,39 \\
\hline 9 & Papel e gráfica & 35909 & 0,96 & 24909 & 1,73 & 7214 & 0,61 & 1045 & 0,12 & 2741 & 1,40 \\
\hline 10 & Indústria da borracha & 2024 & 0,05 & 1763 & 0,12 & 261 & 0,02 & - & - & - & - \\
\hline 11 & Química & 27617 & 0,74 & 22690 & 1,57 & 4143 & 0,35 & - & - & 784 & 0,40 \\
\hline 12 & Farm. e perfumaria & 3329 & 0,09 & 3329 & 0,23 & - & - & - & - & - & - \\
\hline 13 & Artigos de plástico & 12050 & 0,32 & 9667 & 0,67 & 2.383 & 0,20 & - & - & - & - \\
\hline 14 & Indústria têxtil & 10024 & 0,27 & 5879 & 0,41 & 2644 & 0,22 & 1240 & 0,14 & 261 & 0,13 \\
\hline 15 & Artigos do vestuário & 103410 & 2,78 & 32471 & 2,25 & 14135 & 1,19 & 48347 & 5,37 & 8457 & 4,33 \\
\hline 16 & Fabricação de calçados & 3523 & 0,09 & 1761 & 0,12 & 1762 & 0,15 & - & - & 0 & - \\
\hline 17 & Ind. prod. alim., beb. e fumo & 115634 & 3,10 & 84336 & 5,85 & 17556 & 1,48 & 7147 & 0,79 & 6595 & 3,37 \\
\hline 18 & Indústrias diversas & 21609 & 0,58 & 9792 & 0,68 & 6101 & 0,51 & 3430 & 0,38 & 2286 & 1,17 \\
\hline 19 & Serviços ind. utilid. públ. & 29708 & 0,80 & 20466 & 1,42 & 9242 & 0,78 & - & - & - & - \\
\hline 20 & Construção civil & 307066 & 8,24 & 76131 & 5,28 & 81149 & 6,84 & 132164 & 14,67 & 17622 & 9,02 \\
\hline 21 & Comércio & 587045 & 15,76 & 247378 & 17,15 & 100474 & 8,47 & 184452 & 20,48 & 54741 & 28,01 \\
\hline 22 & Transportes & 150316 & 4,04 & 68520 & 4,75 & 26605 & 2,24 & 50522 & 5,61 & 4669 & 2,39 \\
\hline 23 & Comunicações & 22861 & 0,61 & 15382 & 1,07 & 6694 & 0,56 & 523 & 0,06 & 262 & 0,13 \\
\hline 24 & Instituições financeiras & 46166 & 1,24 & 34379 & 2,38 & 8719 & 0,74 & 1046 & 0,12 & 2022 & 1,03 \\
\hline 25 & Serviços & 939051 & 25,21 & 319626 & 22,15 & 387150 & 32,65 & 181117 & 20,11 & 51158 & 26,17 \\
\hline 26 & Aluguel de imóveis & 21165 & 0,57 & 9996 & 0,69 & 2809 & 0,24 & 5191 & 0,58 & 3169 & 1,62 \\
\hline 27 & Administração pública & 374658 & 10,06 & 147384 & 10,22 & 225086 & 18,98 & 1665 & 0,18 & 523 & 0,27 \\
\hline \multirow[t]{2}{*}{28} & Serv. priv. não-mercantis & 44649 & 1,20 & 22881 & 1,59 & 20267 & 1,71 & 1501 & 0,17 & - & - \\
\hline & TOTAL & 3.724846 & 100,00 & 1442814 & 100,00 & 1185907 & 100,00 & 900659 & 100,00 & 195466 & 100,00 \\
\hline
\end{tabular}

FONTE: IBGE - PNAD.

Os três setores apresentados acima são caracterizados como grandes empregadores de mão-de-obra. A maioria dos setores industriais é intensiva na utilização da mão-de-obra. Nesse sentido, este trabalho se dirige principalmente ao Setor Industrial e, em especial, à indústria de Madeira e Mobiliário e Papel e Gráfica.

Na Tabela 2 tem-se a quantidade de pessoas ocupadas na indústria por atividade. A indústria corresponde a $15,73 \%$ das pessoas ocupadas no Paraná. A principal atividade empregadora é a Indústria de Produtos Alimentares, Bebida e Fumo, com 19,73\% das pessoas ocupadas na indústria. A segunda e a terceira classificações no ranking ficaram para a indústria de Madeira e Mobiliário e Artigos do Vestuário. A indústria de Papel e Gráfica ficou na quinta colocação. Como a indústria de Papel e Celulose é um setor intensivo de mão-de-obra, essa colocação foi possivelmente influenciada pela 
indústria Gráfica, que, por se constituir de empresas de pequeno e de médio portes, é menos intensiva em mão-de-obra que a indústria de Papel.

Tabela 2 - PESSOAL OCUPADO NA INDÚSTRIA PARANAENSE - 1998

\begin{tabular}{ll|c|c|c}
\hline \multicolumn{1}{c|}{ ATIVIDADE } & $\begin{array}{c}\text { PESSOAL } \\
\text { OCUPADO }\end{array}$ & $\%$ & POSIÇ̃̃̃ \\
\hline 17 & Indústria de produtos alimentares, bebida e fumo & 115634 & 19,73 & 1 \\
8 & Madeira e mobiliário & 115465 & 19,71 & 2 \\
15 & Artigos do vestuário & 103410 & 17,65 & 3 \\
4 & Siderurgia & 51591 & 8,8 & 4 \\
9 & Papel e gráfica & 35909 & 6,13 & 5 \\
11 & Química & 27617 & 4,71 & 6 \\
6 & Metalurgia & 24101 & 4,11 & 7 \\
3 & Minerais não-metálicos & 23805 & 4,06 & 8 \\
5 & Máquinas e tratores & 23807 & 4,06 & 9 \\
18 & Indústrias diversas & 21609 & 3,69 & 11 \\
7 & Material elétrico e equipamentos eletrônicos & 12051 & 2,06 & 12 \\
13 & Artigos de plástico & 12050 & 2,06 & 13 \\
14 & Indústria têxtil & 10024 & 1,71 & 14 \\
16 & Fabricação de calçados & 3523 & 0,6 & 15 \\
12 & Farmacêutica e perfumaria & 3329 & 0,57 & 16 \\
10 & Indústria da borracha & 2024 & 0,35 & \\
& TOTAL & 585949 & 100,00 & \\
\hline
\end{tabular}

FONTE: IBGE - PNAD.

Com os dados de emprego foram calculados os multiplicadores do Tipo I, Tipo II e o efeito renda. As metodologias e os resultados são expostos a seguir. Os multiplicadores da matriz de contabilidade social encontram-se nos anexos I e II. A matriz foi desenvolvida por Caballero Nuñez e Kureski (2004).

\section{Multiplicador de emprego do tipo I}

Este multiplicador tem o objetivo de demonstrar para a atividade $\mathrm{j}$ o volume de emprego direto e indireto resultante do aumento de uma unidade monetária na demanda final. Para obter o multiplicador, primeiramente é necessário obter a matriz de Leontief. Essa matriz é dada pela seguinte fórmula:

$$
X=(I-A)^{-1} \cdot Y
$$

Em que:

$\mathrm{X}=$ Valor bruto da Produção

$\mathrm{I}=$ Matriz identidade

A = Matriz dos coeficientes técnicos diretos 
Segundo Thorbecke (1998, p. 396), os coeficientes técnicos diretos (Matriz A) correspondem à matriz dos multiplicares contábeis diretos (Matriz $\mathrm{T}_{11}$, quadro 2.1.1). Logo:

$$
\mathrm{A}=\mathrm{T}_{11}
$$

Substituindo em (3.1):

$$
\mathrm{X}=\left(\mathrm{I}-\mathrm{T}_{11}\right)^{-1} \cdot \mathrm{Y}
$$

Em que:

$\mathrm{X}=$ Valor bruto da produção

$\mathrm{I}=$ Matriz identidade

A = Matriz dos multiplicadores contábeis diretos

$\mathrm{Y}=$ Demanda final

Assim, obtém-se por meio da fórmula (3.1.3) a matriz de Leontief. A seguir, foram obtidos os coeficientes de emprego direto, que é dado por:

$$
\mathrm{I}_{\mathrm{j}}=\mathrm{e}_{\mathrm{j}} / \mathrm{x}_{\mathrm{j}}
$$

Em que:

$1_{\mathrm{j}}=$ Coeficiente de emprego direto

$\mathrm{e}_{\mathrm{j}}=$ Número de empregados da atividade $\mathrm{j}$

$\mathrm{x}_{\mathrm{j}}=$ Valor bruto da produção da atividade $\mathrm{j}$

Com a fórmula (3.1.4), obtêm-se os coeficientes técnicos de emprego diretos. Para obtê-los, aplica-se a seguinte fórmula:

$$
\mathrm{CE}=\mathrm{L}\left(\mathrm{I}-\mathrm{T}_{11}\right)^{-1} \text {. } \mathrm{Y}
$$

Em que:

$\mathrm{CE}=$ Coeficientes técnicos de emprego direto e indireto

$\mathrm{L}=$ Coeficientes técnicos de emprego direto

$\mathrm{I}=$ Matriz identidade

$\mathrm{T}_{11}=$ Matriz dos multiplicares contábeis diretos

$\mathrm{Y}=$ Demanda final

Utilizando-se os dados da Pnad e da Matriz de Contabilidade Social do Paraná, estimou-se o multiplicador de emprego direto e indireto ou multiplicador do tipo I, para aumento de R \$ 1 milhão na demanda final paranaense. A atividade Serviços Privados Não-Mercantis foi excluída da análise, porque o seu pequeno valor da produção e o elevado número de trabalhadores distorcem os resultados. Esse procedimento também foi adotado por Najberg (1999).

Na Tabela 3, têm-se os multiplicadores de emprego direto e indireto para o conjunto da economia paranaense. A principal atividade geradora de emprego é Artigos do Vestuário, com um coeficiente técnico de 970,11 empregos para o aumento de R 1 milhão na sua demanda final. Ao se consi- 
derar nessa atividade o coeficiente técnico total, pode-se incorrer em erro. Os dados de emprego da Pnad englobam todas as costureiras, tanto as que trabalham em empresas quanto as que trabalham por conta própria. Entretanto, o valor bruto da produção, calculado nas Contas Regionais, não consegue mensurar adequadamente a produção gerada pelos empregados por conta própria. Como é característica dessa atividade possuir uma participação no número de empregados por conta própria, resulta em um multiplicador de emprego superestimado. É mais sensato utilizar, neste caso, o multiplicador de empregados com carteira assinada (307,42 empregos para o aumento de R \$ 1 milhão na sua demanda final), para fins de políticas industriais dentro das atividades.

Tabela 3 - GERAÇÃO DE EMPREGO DO TIPO I, SEGUNDO A ATIVIDADE, NO PARANÁ - 1998

\begin{tabular}{|c|c|c|c|c|c|c|c|}
\hline & & & EFICIENTE & TÉCNICO I & E EMPR & GO & \\
\hline & ATIVIDADE & & Empregado & Empregado & Conta & & POSIÇÃO \\
\hline 15 & Artigos do vestuário & 970.11 & 307,42 & 134,24 & 449,3 & 79,15 & 1 \\
\hline 25 & Serviços & 285,38 & 98,07 & 116,21 & 55,53 & 15,58 & 2 \\
\hline 2 & Extrativa mineral & 123,61 & 86,78 & 16,33 & 4,93 & 15,57 & 3 \\
\hline 18 & Indústrias diversas & 86,57 & 38,91 & 23,49 & 15,72 & 8,46 & 4 \\
\hline 21 & Comércio & 71,47 & 30,53 & 13,46 & 21,27 & 6,21 & 5 \\
\hline 9 & Papel e gráfica & 71,03 & 38,01 & 15,28 & 12,32 & 5,42 & 6 \\
\hline 1 & Agropecuária & 70,36 & 15,3 & 23,75 & 28,34 & 2,98 & 7 \\
\hline 22 & Transportes & 61,13 & 28,07 & 11,77 & 18,94 & 2,36 & 8 \\
\hline 8 & Madeira e mobiliário & 59,56 & 28,77 & 13,8 & 13,74 & 3,24 & 9 \\
\hline 4 & Siderurgia & 59,47 & 37,08 & 10,99 & 4,54 & 6,87 & 10 \\
\hline 27 & Administração pública & 57,6 & 22,75 & 30,16 & 3,68 & 1,01 & 11 \\
\hline 16 & Fabricação de calçados & 56,66 & 26,61 & 19,71 & 8,08 & 2,25 & 12 \\
\hline 14 & Indústria têxtil & 56,41 & 27,57 & 13,43 & 12,36 & 3,04 & 13 \\
\hline 24 & Instituições financeiras & 53,69 & 31,3 & 14,3 & 5,47 & 2,61 & 14 \\
\hline 17 & $\begin{array}{l}\text { Indústria de produtos alimentares, bebida e } \\
\text { fumo }\end{array}$ & 46,7 & 17,78 & 12,44 & 13,87 & 2,61 & 15 \\
\hline 13 & Artigos de plástico & 44,63 & 30,24 & 8,98 & 4,19 & 1,23 & 16 \\
\hline 3 & Minerais não-metálicos & 38,55 & 20,98 & 8,76 & 5,51 & 3,3 & 17 \\
\hline 12 & Farmacêutica e perfumaria & 37,98 & 21,58 & 6,3 & 7,89 & 2,21 & 18 \\
\hline 6 & Metalurgia & 35,54 & 24,29 & 4,64 & 4,86 & 1,74 & 19 \\
\hline 20 & Construção civil & 33,44 & 10,98 & 8,47 & 11,89 & 2,11 & 20 \\
\hline 7 & Material elétrico e equipamentos eletrônicos & 28,16 & 19,47 & 3,86 & 3,65 & 1,18 & 21 \\
\hline 5 & Máquinas e tratores & 26,93 & 15,28 & 4,78 & 4,58 & 2,29 & 22 \\
\hline 10 & Indústria da borracha & 23,15 & 13,7 & 4,32 & 4,09 & 1,04 & 23 \\
\hline 11 & Química & 23,01 & 11,74 & 4,89 & 5 & 1,38 & 24 \\
\hline 23 & Comunicações & 19,31 & 11,85 & 5,61 & 1,4 & 0,45 & 25 \\
\hline 19 & Serviços industriais de utilidade pública & 15,88 & 9,82 & 4,69 & 1,02 & 0,34 & 26 \\
\hline 26 & Aluguel de imóveis & 4,02 & 1,73 & 0,72 & 1,1 & 0,47 & 27 \\
\hline
\end{tabular}

FONTES: Matriz de Contabilidade Social do Paraná, PNAD.

NOTA: Geração direta e indireta de emprego por R 1 milhão. Cálculos do autor. 
O segundo e o terceiro lugares ficam para as atividades Serviços (25) e Extrativa Mineral (12), as quais têm como característica principal o uso intensivo de mão-de-obra. Quando se isolam somente as atividades relacionadas à Indústria de Transformação, a primeira colocação fica para a atividade de Artigos de Vestuário. O último lugar é da Indústria Química (11). A razão para essa colocação é que a maior parte da produção da Indústria Química paranaense está concentrada na Refinaria Getúlio Vargas, localizada no município de Araucária, Região Metropolitana de Curitiba. A refinaria por si só não é uma grande geradora de empregos, sendo necessária a instalação de um pólo petroquímico para a alavancagem do emprego na atividade. A indústria de Papel e Gráfica (9) e a de Madeira e Mobiliário (8) estão classificadas na terceira e na quarta posições, respectivamente. No caso da primeira, provavelmente o emprego vem sendo puxado pelo setor gráfico, com predominância de empregados com carteira assinada. No segundo caso, a atividade tem quase $50 \%$ dos empregos gerados com trabalhadores sem carteira e por conta própria.

\section{Multiplicador de emprego do tipo II}

O multiplicador do tipo II difere do multiplicador do tipo I por incluir o efeito renda. A utilização da Matriz de Relações Intersetoriais para o cálculo desse multiplicador é dificultada em razão da necessidade de se tornar endógena a variável Consumo das Famílias. Segundo O'Connor (1995, p. 62), a inclusão do rendimentos das famílias na matriz intersetorial apresenta alguns problemas técnicos porque, além da coluna das famílias que já existe no quadrante da demanda final, deve ser incluída uma linha para manter a matriz quadrada. Essa linha não existe na tabela de relações intersetoriais tradicional e deve ser derivada dos elementos de salários, ordenados e de lucros, visto que estes são as principais fontes de rendimento das famílias. Essa dificuldade pode ser também contornada utilizando-se uma Matriz de Contabilidade Social, na qual o consumo das famílias é uma variável endógena.

Thorbecke (1998, p. 300) refere-se à MCS para estimar os efeitos do incremento da demanda nas variáveis exógenas (investimento, gasto do governo e exportação) sobre a capacidade ociosa, emprego e recursos não utilizados. O multiplicador da MCS difere do multiplicador da matriz de insumoproduto porque torna endógena a conta-consumo das famílias multiplicadoras de emprego contábil. Assim, por meio da MCS, obtém-se o multiplicador do tipo II, podendo-se estimar não somente os efeitos direto e indireto 
do aumento da demanda final, mas também a variação induzida resultante dos aumento dos gastos dos consumidores.

O multiplicador do tipo II demostra para a atividade j o volume de emprego resultante do aumento de uma unidade monetária na demanda final. Nesse caso, a demanda final é composta por valor dos investimentos, gastos do governo e exportação. A fonte de dados para se obter esse multiplicador é uma Matriz de Contabilidade Social. A matriz dos multiplicadores contábeis é representada por:

$$
Y_{n}=\left(I-A_{n}\right)^{-1} f
$$

Em que:

$\mathrm{Y}_{\mathrm{n}}=$ Valor das rendas

$\mathrm{I}=$ Matriz identidade

$\mathrm{A}_{\mathrm{n}}=$ Coeficiente técnico direto

$\left(\mathrm{I}-\mathrm{A}_{\mathrm{n}}\right)^{-1}=$ Matriz dos multiplicadores contábeis

$\mathrm{f}=$ Somatório das variáveis exógenas

Como se deseja obter a matriz dos multiplicadores de empregos do tipo II, é necessário primeiramente obter os coeficientes diretos de emprego, que são dados por:

$$
\mathrm{I}_{\mathrm{j}}=\mathrm{e}_{\mathrm{j}} / \mathrm{x}_{\mathrm{j}}
$$

Em que:

$1_{\mathrm{j}}=$ Multiplicador de emprego direto

$\mathrm{e}_{\mathrm{j}}=$ Número de empregados da atividade $\mathrm{j}$

$\mathrm{x}_{\mathrm{j}}=$ Valor bruto da produção da atividade $\mathrm{j}$

Multiplicando o multiplicador técnico de emprego direto pela matriz dos multiplicadores do tipo II, tem-se:

$$
\operatorname{MCE}=L\left(I-A_{n}\right)^{-1} f
$$

Em que:

$\mathrm{MCE}=$ Multiplicador do tipo II de emprego

$\mathrm{L}=$ Multiplicador de emprego direto

$\mathrm{I}=$ Matriz identidade

$\left(\mathrm{I}-\mathrm{A}_{\mathrm{n}}\right)^{-1}=$ Matriz dos multiplicadores do tipo II

$\mathrm{f}=$ Somatório das variáveis exógenas

Utilizando-se a Matriz de Contabilidade Social do Estado do Paraná, foram estimados os multiplicadores contábeis de emprego. Os três primeiros lugares se mantiveram: Artigos de Vestuário (15), Serviços (25) e Extrativa Mineral (2) - Tabela 4. Ocorreu uma mudança no que se refere às atividades relacionadas que compõem o Setor Terciário: Comércio (21), Transporte (22), Comunicações (23), Instituições Financeiras (24), Serviços (25), 
Aluguel de Imóveis (26) e Administração Pública (27). Essas atividades tiveram aumento expressivo no número de empregos gerados quando o consumo das famílias se tornou uma variável endógena. É o caso da Administração Pública (27), que gerava 57,60 empregos para cada 1 milhão no aumento da demanda final e passou para 127,44 empregos. O impulso do Setor Terciário está relacionado com o efeito-renda, que será abordado a seguir.

Tabela 4 - GERAÇÃO DE EMPREGO DO TIPO II, SEGUNDO A ATIVIDADE, NO PARANÁ - 1998

\begin{tabular}{|c|c|c|c|c|c|c|c|}
\hline \multirow{2}{*}{\multicolumn{2}{|c|}{ ATIVIDADE }} & \multicolumn{5}{|c|}{ MULTIPLICADOR CONTÁBIL DE EMPREGO } & \multirow[b]{2}{*}{ POSIÇÃo } \\
\hline & & \multirow{2}{*}{$\begin{array}{c}\text { TOTAL } \\
999,36\end{array}$} & \multirow{2}{*}{\begin{tabular}{|c|}
$\begin{array}{c}\text { Empregado } \\
\text { com carteira }\end{array}$ \\
318,57
\end{tabular}} & \multirow{2}{*}{$\frac{\mid \begin{array}{c}\text { Empregado } \\
\text { sem carteira }\end{array}}{143,34}$} & \multirow{2}{*}{$\begin{array}{c}\begin{array}{c}\text { Conta } \\
\text { própria }\end{array} \\
456,71\end{array}$} & Empregador & \\
\hline 15 & Artigos do vestuário & & & & & 80,74 & 1 \\
\hline 25 & Serviços & 343,16 & 120,1 & 134,18 & 70,17 & 18,71 & 2 \\
\hline 2 & Extrativa mineral & 149,72 & 96,74 & 24,46 & 11,55 & 16,98 & 3 \\
\hline 27 & Administração pública & 127,44 & 49,38 & 51,88 & 21,38 & 4,8 & 4 \\
\hline 1 & Agropecuária & 124,3 & 35,86 & 40,53 & 42,01 & 5,9 & 5 \\
\hline 24 & Instituições financeiras & 117,48 & 55,62 & 34,15 & 21,63 & 6,08 & 6 \\
\hline 22 & Transportes & 117,08 & 49,4 & 29,18 & 33,11 & 5,39 & 7 \\
\hline 18 & Indústrias diversas & 116,94 & 50,49 & 32,93 & 23,41 & 10,11 & 8 \\
\hline 21 & Comércio & 105,57 & 43,53 & 24,07 & 29,91 & 8,06 & 9 \\
\hline 9 & Papel e gráfica & 101,76 & 49,72 & 24,84 & 20,11 & 7,09 & 10 \\
\hline 8 & Madeira e mobiliário & 98,72 & 43,7 & 25,99 & 23,66 & 5,37 & 11 \\
\hline 4 & Siderurgia & 95,04 & 50,64 & 22,05 & 13,55 & 8,8 & 12 \\
\hline 14 & Indústria têxtil & 88,85 & 39,94 & 23,52 & 20,58 & 4,8 & 13 \\
\hline 16 & Fabricação de calçados & 88,22 & 38,64 & 29,53 & 16,08 & 3,96 & 14 \\
\hline 17 & Indústria de produtos alimentares, bebida e fumo & 85,32 & 32,51 & 24,45 & 23,66 & 4,7 & 15 \\
\hline 3 & Minerais não-metálicos & 80,54 & 36,99 & 21,83 & 16,15 & 5,58 & 16 \\
\hline 20 & Construção civil & 78,47 & 28,14 & 22,48 & 23,29 & 4,56 & 17 \\
\hline 13 & Artigos de plástico & 74,66 & 41,68 & 18,32 & 11,8 & 2,86 & 18 \\
\hline 23 & Comunicações & 70,08 & 31,21 & 21,41 & 14,26 & 3,21 & 19 \\
\hline 19 & Serviços Ind. Utilidade Pública & 69,36 & 30,21 & 21,33 & 14,57 & 3,25 & 20 \\
\hline 6 & Metalurgia & 66,95 & 36,27 & 14,42 & 12,82 & 3,45 & 21 \\
\hline 12 & Farmacêutica e perfumaria & 66,21 & 32,35 & 15,08 & 15,04 & 3,74 & 22 \\
\hline 11 & Química & 63,15 & 27,04 & 17,38 & 15,17 & 3,56 & 23 \\
\hline 5 & Máquinas e tratores & 63,13 & 29,08 & 16,04 & 13,75 & 4,26 & 24 \\
\hline 26 & Aluguel de imóveis & 63,05 & 24,23 & 19,09 & 16,06 & 3,67 & 25 \\
\hline 7 & Material elétrico e equipamentos eletrônicos & 53,46 & 29,11 & 11,73 & 10,06 & 2,56 & 26 \\
\hline 10 & Indústria da borracha & 49,61 & 23,78 & 12,55 & 10,8 & 2,47 & 27 \\
\hline
\end{tabular}

FONTES: Matriz de Contabilidade Social do Paraná, PNAD. NOTA: Geração de emprego por R\$ 1 milhão. Cálculo do autor.

\section{Efeito-renda na geração de empregos}

Parte do valor adicionado gerado pela empresa é paga aos trabalhadores, em forma de salários, e aos empresários, em forma de lucro e dividendos. Esses pagamentos constituem a renda da família, que é gasta em consumo final. Para atender ao consumo final das famílias, as empresas incrementam sua produção, contratando novos funcionários e comprando 
insumo de outras empresas, gerando assim empregos diretos e indiretos dentro da cadeia produtiva. A contratação de novos trabalhadores, em razão do aumento na demanda final, é considerada o efeito-renda, isso porque o aumento da demanda final é resultado do aumento da renda das famílias. O efeito-renda é calculado da seguinte forma:

Em que:

$\mathrm{ER}=$ Efeito Renda no emprego

$\mathrm{MCE}=$ Multiplicador de emprego do tipo II

$\mathrm{CE}=$ Multiplicador de emprego direto e indireto

A partir do resultado de ER, tem-se o multiplicador de efeito-renda para o aumento de 1 milhão na demanda final. Segundo Najberg (1999), existem dois fatores que determinam a classificação das atividades:

a) a elevada participação do valor adicionado no valor da produção, que é o caso das atividades do Setor Terciário;

b) o número de empregos diretos e indiretos gerados. Em razão do processo de realimentação do modelo, provocado pelas equações simultâneas, pelo efeito-renda calcula-se o número de empregos gerados a partir do consumo dos trabalhadores adicionais contratados.

A Tabela 5 demonstra os resultados referentes ao efeito-renda. Dos 10 primeiros colocados, apenas dois não pertencem ao Setor Terciário. Nesse caso, a Indústria de Vestuário (15) não lidera o multiplicador de emprego. A primeira colocação ficou com a Administração Pública (27), seguida das Instituições Financeiras (24). A primeira colocação da Administração Pública está ligada ao procedimento metodológico do cálculo da renda desta atividade. Quase toda a renda é considerada salário, impulsionando o efeitorenda. Já nas Instituições Financeiras os salários mais elevados proporcionam uma elevada participação deste na produção total, resultando em um multiplicador de renda mais elevado. Se comparado o multiplicador de renda com o multiplicador de emprego do tipo I, a Administração Pública salta da 11. a $^{\mathrm{a}}$ ara a 1 . $^{\mathrm{a}}$ colocação, e as Instituições Financeiras saltam da $14 .{ }^{\mathrm{a}}$ para a $2 .{ }^{\mathrm{a}}$ colocação.

Quanto à Indústria de Transformação, a atividade de Artigos de Vestuário (15) é ultrapassada pela atividade de Minerais Não-Metálicos (3), influenciada principalmente pelas baixa renda do Setor. A atividade de Minerais Não-Metálicos (3) foi impulsionada por sua forte ligação com a indústria da Construção Civil (20), sendo a nona colocada. Com relação à atividade de Papel e Gráfica (9) e Madeira e Mobiliária (8), a primeira teve perdas na colocação, visto que possui baixa participação no valor adicionado no valor 
bruto da produção, em face da utilização de capital mais intensivo. Assim, passou da 6. ${ }^{a}$ para a 20. ${ }^{a}$ posição, quando se compara o multiplicador de emprego do tipo I com o multiplicador do efeito-renda. Fazendo a mesma relação para a atividade Madeira e Mobiliária (8), esta passou da 9. ${ }^{\mathrm{a}}$ para a 12. ${ }^{a}$ posição. A mudança não foi tão expressiva, por se tratar de uma atividade que engloba médias e pequenas empresas, que utilizam mão-de-obra mais intensivamente, resultando em uma relação entre a renda e o valor bruto da produção maior que a atividade de Papel e Gráfica.

Em resumo, a análise precedente descreveu os impactos do aumento da demanda final, por meio dos multiplicadores de emprego do tipo I e do tipo II e o efeito-renda. Por meio dos multiplicadores, verificou-se, principalmente, a diferenciação que se estabelece entre eles, quando da utilização da conta consumo das famílias como variável endógena e sua repercussão na geração de emprego.

Tabela 5 - $\quad$ EFEITO RENDA NA GERAÇÃO DE EMPREGO, SEGUNDO A ATIVIDADE, NO PARANÁ - 1998

\begin{tabular}{|c|c|c|c|c|c|c|c|}
\hline \multirow{2}{*}{\multicolumn{2}{|c|}{ ATIVIDADE }} & \multicolumn{5}{|c|}{ EFEITO RENDA } & \multirow[b]{2}{*}{ POSIÇÃO } \\
\hline & & TOTAL & $\begin{array}{l}\text { Empregado } \\
\text { com carteira }\end{array}$ & $\begin{array}{l}\text { Empregado } \\
\text { sem carteira }\end{array}$ & $\begin{array}{l}\text { Conta } \\
\text { própria }\end{array}$ & Empregador & \\
\hline 27 & Administração pública & 69,84 & 26,62 & 21,73 & 17,69 & 3,79 & 1 \\
\hline 24 & Instituições financeiras & 63,79 & 24,32 & 19,85 & 16,16 & 3,46 & 2 \\
\hline 26 & Aluguel de imóveis & 59,04 & 22,51 & 18,37 & 14,96 & 3,2 & 3 \\
\hline 25 & Serviços & 57,78 & 22,03 & 17,98 & 14,64 & 3,14 & 4 \\
\hline 22 & Transportes & 55,95 & 21,33 & 17,41 & 14,18 & 3,04 & 5 \\
\hline 1 & Agropecuária & 53,94 & 20,56 & 16,78 & 13,67 & 2,93 & 6 \\
\hline 19 & Serviços ind. Utilidade Pública & 53,48 & 20,39 & 16,64 & 13,55 & 2,9 & 7 \\
\hline 23 & Comunicações & 50,77 & 19,35 & 15,79 & 12,86 & 2,76 & 8 \\
\hline 20 & Construção civil & 45,02 & 17,16 & 14,01 & 11,41 & 2,44 & 9 \\
\hline 3 & Minerais não-metálicos & 41,99 & 16,01 & 13,06 & 10,64 & 2,28 & 10 \\
\hline 11 & Química & 40,14 & 15,3 & 12,49 & 10,17 & 2,18 & 11 \\
\hline 8 & Madeira e mobiliário & 39,16 & 14,93 & 12,18 & 9,92 & 2,13 & 12 \\
\hline 17 & Indústria de produtos alimentares, bebida e fumo & 38,62 & 14,72 & 12,01 & 9,78 & 2,1 & 13 \\
\hline 5 & Máquinas e tratores & 36,2 & 13,8 & 11,26 & 9,17 & 1,96 & 14 \\
\hline 4 & Siderurgia & 35,57 & 13,56 & 11,07 & 9,01 & 1,93 & 15 \\
\hline 21 & Comércio & 34,11 & 13 & 10,61 & 8,64 & 1,85 & 16 \\
\hline 14 & Indústria têxtil & 32,44 & 12,37 & 10,09 & 8,22 & 1,76 & 17 \\
\hline 16 & Fabricação de calçados & 31,56 & 12,03 & 9,82 & 8,00 & 1,71 & 18 \\
\hline 6 & Metalurgia & 31,41 & 11,97 & 9,77 & 7,96 & 1,7 & 19 \\
\hline 9 & Papel e gráfica & 30,73 & 11,72 & 9,56 & 7,79 & 1,67 & 20 \\
\hline 18 & Indústrias diversas & 30,37 & 11,58 & 9,45 & 7,69 & 1,65 & 21 \\
\hline 13 & Artigos de plástico & 30,03 & 11,45 & 9,34 & 7,61 & 1,63 & 22 \\
\hline 15 & Artigos do vestuário & 29,25 & 11,15 & 9,1 & 7,41 & 1,59 & 23 \\
\hline 12 & Farmacêutica e perfumaria & 28,23 & 10,76 & 8,78 & 7,15 & 1,53 & 24 \\
\hline 10 & Indústria da borracha & 26,46 & 10,09 & 8,23 & 6,7 & 1,44 & 25 \\
\hline 2 & Extrativa mineral & 26,11 & 9,95 & 8,12 & 6,62 & 1,42 & 26 \\
\hline 7 & Material elétrico e equipamentos eletrônicos & 25,3 & 9,65 & 7,87 & 6,41 & 1,37 & 27 \\
\hline
\end{tabular}

FONTES: Matriz de Contabilidade Social do Paraná, PNAD.

NOTA: Geração direta e indireta de emprego por R\$ 1 milhão. Cálculos do autor. 


\section{Decomposição do multiplicador de emprego}

A geração do emprego dentro das atividades econômicas tem como ponto de partida o aumento da demanda final - neste caso, de 1 milhão de reais. Primeiramente, são gerados os empregos diretos, que correspondem à divisão do total de empregados pelo valor bruto da produção da atividade. Esse procedimento é descrito pela seguinte fórmula:

$$
\mathrm{I}_{\mathrm{j}}=\mathrm{e}_{\mathrm{j}} / \mathrm{x}_{\mathrm{j}}
$$

Em que:

$1_{\mathrm{j}}=$ Coeficiente de emprego direto

$\mathrm{e}_{\mathrm{j}}=$ Número de empregados da atividade $\mathrm{j}$

$\mathrm{x}_{\mathrm{j}}=$ Valor bruto da produção da atividade $\mathrm{j}$

A demanda por insumos intermediários da atividade que teve aumento da demanda final resulta no aumento da produção das demais atividades. Denomina-se esse incremento da produção como primeira rodada. Mas a atividade fornecedora de insumo também comprará mais insumo para atender ao incremento da sua produção. Tem-se, então, a segunda rodada.

O número de rodadas na economia é infinito. Cada novo incremento na compra de insumos gera empregos indiretos. Para medir o emprego indireto é necessária a matriz de Leontief:

$$
\mathrm{CEDI}=\mathrm{L}\left(\mathrm{I}-\mathrm{T}_{11}\right)^{-1} \mathrm{Y}
$$

Em que:

CEDI $=$ Multiplicador de emprego direto e indireto

$\mathrm{L}=$ Multiplicador de emprego direto

$\mathrm{I}=$ Matriz identidade

$\mathrm{T}_{11}=$ matriz dos multiplicadores diretos

$\mathrm{Y}=$ Demanda Final

Entretanto, a fórmula (3.4.2) fornece o multiplicador de empregos diretos e indiretos gerados ou multiplicador do tipo I de emprego. É necessário, então, diminuir do total de empregos os empregos diretos, obtendo-se, assim, o coeficiente de empregos indiretos.

$$
\mathrm{CEI}=\mathrm{CEDI}-\mathrm{Cl}
$$

Em que:

$\mathrm{CEI}=$ Multiplicador de emprego indireto

$\mathrm{CEDI}=$ Multiplicador de emprego direto e indireto

$\mathrm{Cl}=$ Multiplicador de emprego direto

O incremento no aumento da produção também resulta no aumento do emprego decorrente do aumento da renda, ou seja, o efeito-renda. As 
pessoas que ocupam os novos postos de trabalho recebem salários que utilizam na compra de produtos para satisfação de suas necessidades, gerando um novo acréscimo na demanda final e de novos empregos.

Endogeniza-se a variável consumo das famílias, utilizando-se o multiplicador da Matriz de Contabilidade Social do Paraná, para calcular o efeito-renda.

$$
M C E=L\left(I-A_{n}\right)^{-1} f
$$

Em que:

$\mathrm{MCE}=$ Multiplicador do tipo II

$\mathrm{L}=$ Multiplicador de emprego direto

$\mathrm{I}=$ Matriz identidade

$\left(\mathrm{I}-\mathrm{A}_{\mathrm{n}}\right)^{-1}=$ Matriz dos multiplicadores do tipo II

$\mathrm{f}=$ Somatório das variáveis exógenas

A fórmula (3.4.4) fornece o coeficiente de emprego total gerado pelo aumento da demanda final, incluindo o efeito-renda. Para obter somente o efeito-renda é necessário diminuir desse coeficiente os empregos diretos e indiretos. Assim:

$$
\mathrm{ER}=\mathrm{MCE}-\mathrm{CEDI}
$$

Em que:

$\mathrm{ER}=$ Efeito Renda no emprego

MCE $=$ Multiplicador do tipo II

CEDI $=$ Multiplicador de emprego direto e indireto

Os resultados da decomposição encontram-se na Tabela 6. Pelo fato de ter um alto coeficiente técnico direto, a indústria de Artigos de Vestuário (15) ficou em primeiro lugar na geração de emprego total. Entretanto, nota-se que esse setor gera poucos empregos indiretos, visto que seu principal encadeamento é com a indústria Têxtil (14), que possui baixo coeficiente de emprego direto (21,13 empregos para cada 1 milhão de reais gastos na demanda final). Em segundo lugar ficou o Setor Serviços (25), que engloba a Saúde Mercantil e Educação, Serviços de Alimentação e Hospedagens, entre outros, que são pouco intensivos em mão-de-obra. Nota-se, nesse caso, um aumento expressivo nos empregos em decorrência do efeito-renda, evidenciando o efeito do crescimento da renda junto ao Setor Serviços (ver Tabela 6).

A indústria de Papel e Gráfica (9) ficou na décima posição. O emprego indireto teve maior dinâmica com o incremento da demanda final, ou seja, gera 48,46 empregos para 1 milhão de gastos na demanda final. Esse resultado é mais que o dobro, quando se compara com o coeficiente emprego direto de 22,57 empregos para 1 milhão de reais investido. Esses resulta- 
dos demonstram que as atividades fornecedoras de insumos para outras atividades são menos intensivas em mão-de-obra, como é o caso da Agropecuária (ver Tabela 6).

Com relação à indústria de Madeira e Mobiliário (8), esta ficou na décima-primeira posição. O efeito-renda alavanca a geração de emprego. Por ser uma atividade menos intensiva em capital, sua relação entre salários e valor bruto da produção é maior quando se compara com a indústria de Papel e Gráfica (9), impulsionando o efeito-renda. Comparando-se o emprego total das duas atividades, não existiu diferença substancial entre os resultados (ver Tabela 6).

\section{Multiplicador de renda do tipo I}

O multiplicador de renda do tipo I demonstra para a atividade j o volume de renda resultante do aumento de uma unidade monetária na demanda final. Por meio dos dados da Pnad foi possível desagregar a conta de salários em quatro subcontas: empregado com carteira, empregado sem carteira, conta própria e empregador. Contudo, como já explicado neste capítulo, foi necessário agregar algumas atividades. Assim, foram utilizadas as quatro subcontas para estimar os multiplicadores de renda para o Estado. O multiplicador de renda direto e indireto ou multiplicado do tipo I é dado por:

$$
\mathrm{Cr}_{\mathrm{j}}=\mathrm{s}_{\mathrm{j}} / \mathrm{x}_{\mathrm{j}}
$$

Em que:

$\mathrm{cr}_{\mathrm{j}} \quad=$ Multiplicador de renda direto

$\mathrm{s}_{\mathrm{j}} \quad=$ Valor dos salários da atividade $\mathrm{j}$

$\mathrm{x}_{\mathrm{j}} \quad=$ Valor bruto da produção da atividade $\mathrm{j}$ 
NUÑEZ, B. E. C.; KURESKI, R.; PACHECO, C. H. P. Os multiplicadores de emprego e renda...

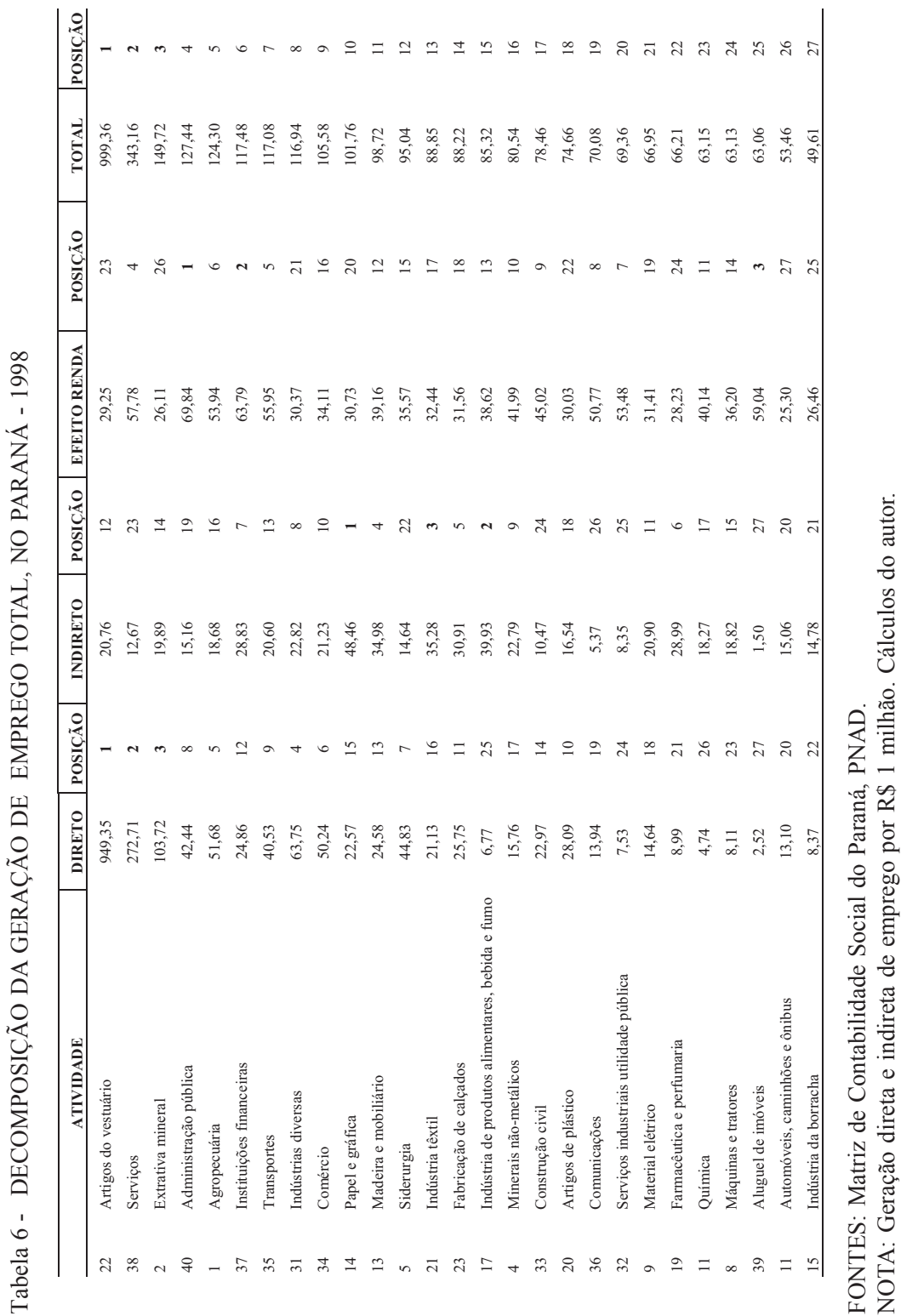


Pela fórmula (3.5.1) são obtidos os coeficientes técnicos de renda diretos. Para calcular os coeficientes técnicos de renda direta e indireta aplica-se a seguinte fórmula:

$$
\mathrm{CW}=\mathrm{CR}\left(\mathrm{I}-\mathrm{T}_{11}\right)^{-1} \cdot \mathrm{Y}
$$

Em que:

$\mathrm{CW}=$ Multiplicador de renda direto e indireto

$\mathrm{CR}=$ Multiplicador de renda direto

$\mathrm{I}=$ Matriz identidade

$\mathrm{T}_{11}=$ Matriz dos multiplicadores diretos

$\mathrm{Y}=$ Demanda Final

A Tabela 7 mostra os multiplicadores de renda do tipo I para o aumento da demanda final de $\mathrm{R} \$ 1$ milhão. Esse multiplicador considera apenas os ganhos referentes a salários, não sendo incluída a parte do lucro. Como o valor adicionado é dividido em salários e lucro, as atividades que tiverem maior proporção do valor adicionado na conta salário têm um multiplicador mais elevado. Nesse caso, refere-se em especial às atividades relacionadas à atividade terciária. Assim, a atividade Administração Pública (28), em face de sua característica de não visar ao lucro, possui o maior multiplicador $-\mathrm{R} \$ 844.119,00$ para um aumento de $\mathrm{R} \$ 1$ milhão da demanda final. Na segunda classificação está a atividade Instituições Financeiras (29). Este Setor possui um multiplicador superior aos demais, dado que os trabalhadores possuem uma renda mais elevada; este é o caso também da atividade Serviço Industrial de Utilidade Pública (20).

Analisando a Indústria de Transformação, a atividade Siderurgia (4) ficou na $6{ }^{a}$ colocação geral, mas na primeira entre o ramo industrial, seguida da atividade Fabricação de Calçados (11). A Atividade Madeira e Mobiliário (8) ocupou a 8. ${ }^{a}$ colocação, superando a Indústria de Papel e Gráfica (9), que ficou na 12. ${ }^{a}$ posição. A diferença de posição é resultado da necessidade de maior acumulação por parte da indústria de papel, em decorrência do maior dispêndio com investimento necessário para a produção de papel.

\section{Multiplicador de renda do tipo II}

O multiplicador de renda do tipo II apresenta para a atividade $\mathrm{j} o$ valor da renda resultante do aumento de uma unidade monetária na demanda final. Consideram-se como demanda final os investimentos, o gasto do governo e as exportações. O consumo das famílias é considerado, neste caso, como variável endógena. O multiplicador é dado por: 


$$
Y_{n}=\left(I-A_{n}\right)^{-1} f
$$

Em que:

$\mathrm{Y}_{\mathrm{n}}=$ Valor das rendas

$\mathrm{I}=$ Matriz identidade

$\mathrm{A}_{\mathrm{n}}=$ Coeficiente técnico direto

$\left(\mathrm{I}-\mathrm{A}_{\mathrm{n}}\right)^{-1}=$ Matriz dos multiplicadores contábeis

$\mathrm{f}=$ Somatório das variáveis exógenas

Tabela 7 - GERAÇÃO DE RENDA DO TIPO I, SEGUNDO ATIVIDADE, NO PARANÁ - 1998

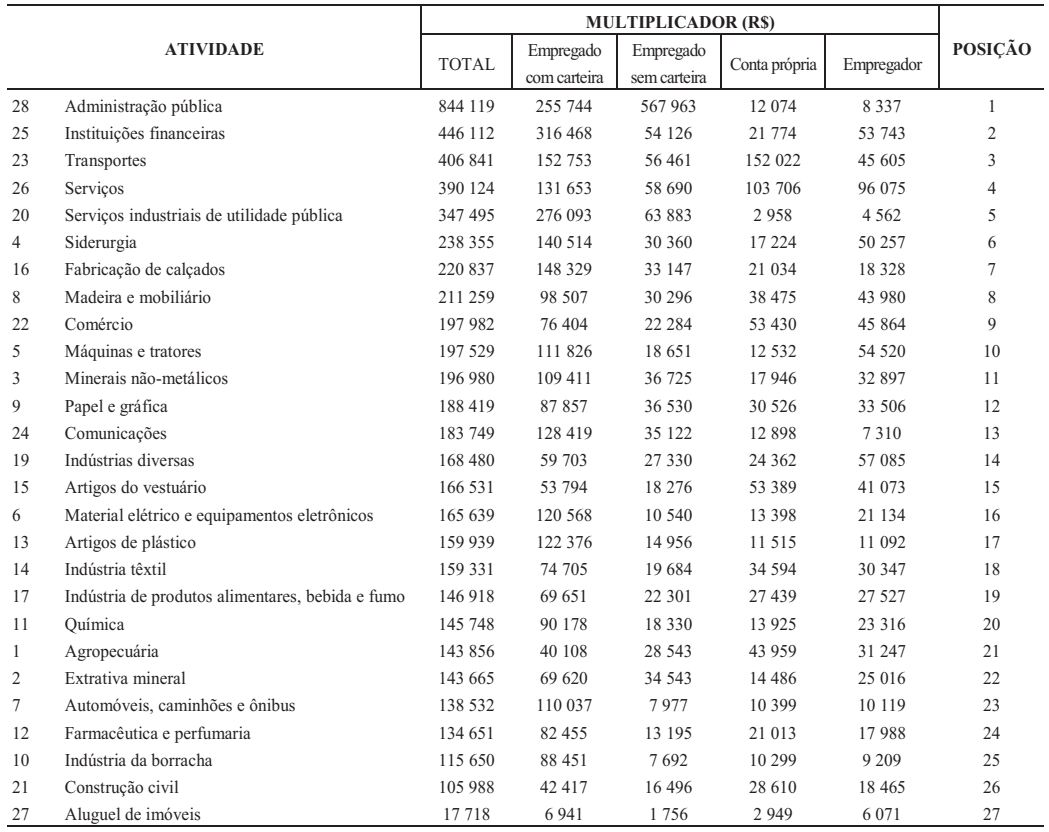

FONTES: Matriz de Contabilidade Social do Paraná, PNAD.

NOTA: Geração direta e indireta de renda por R\$ 1 milhão. Cálculos do autor.

Para obter o resultado do multiplicador basta ler a conta referente aos salários na linha. Assim, utilizando a Matriz de Contabilidade Social do Paraná, tem-se o multiplicador de renda do tipo II (Tabela 8). A classificação não difere do multiplicador de renda do tipo I. A principal diferença está na magnitude do multiplicador, porque o multiplicador do tipo II é resultante da soma entre o multiplicador de renda simples e o efeito-renda. Dessa forma, 
tem-se um incremento no multiplicador da Administração Pública (27) de $114,79 \%$, quando comparado com o multiplicador simples.

Com o objetivo de identificar os efeitos do resultante tratamento da variável Consumo das Famílias como variável endógena, apresenta-se a seguir o efeito-renda.

\section{Efeito-renda na geração da renda}

$\mathrm{O}$ incremento na demanda final faz com que as empresas aumentem a produção, gerando novos empregos e salários. As famílias utilizam a renda para o consumo de bens e serviços finais. As empresas, para atender a essa nova demanda, contratam novos empregados, aos quais pagam salários. Esse incremento de demanda pelas famílias gera também empregos indiretos dentro da cadeia de fornecimento de bens e serviços intermediários. $\mathrm{O}$ total de emprego gerado pelo aumento da demanda final é conseqüência do aumento da renda e é denominado efeito-renda. Então, para medir o coeficiente de renda referente ao aumento de R 1 milhão na demanda final utilizase a seguinte fórmula:

$\mathrm{ER}=\mathrm{CW}-\mathrm{MCR}$

Em que:

$\mathrm{ER}=$ Efeito renda na geração de nova renda

$\mathrm{CW}=$ Multiplicador do tipo I

$\mathrm{MCE}=$ Multiplicador do tipo II 
Tabela 8 - GERAÇÃO DE RENDA DO TIPO II, SEGUNDO A ATIVIDADE, NO PARANÁ - 1998

\begin{tabular}{|c|c|c|c|c|c|c|c|}
\hline \multirow{2}{*}{\multicolumn{2}{|c|}{ ATIVIDADE }} & \multicolumn{5}{|c|}{ MULTIPLICADOR (R\$) } & \multirow[b]{2}{*}{ POSIÇÃO } \\
\hline & & TOTAL & $\begin{array}{c}\text { Empregado } \\
\text { com carteira }\end{array}$ & $\begin{array}{c}\text { Empregado } \\
\text { sem carteira }\end{array}$ & Conta própria & Empregador & \\
\hline 27 & Administração pública & 1057912 & 359413 & 604617 & 51845 & 42038 & 1 \\
\hline 24 & Instituições financeiras & 641387 & 411157 & 87606 & 58100 & 84525 & 2 \\
\hline 22 & Transportes & 578126 & 235809 & 85827 & 183885 & 72605 & 3 \\
\hline 25 & Serviços & 567007 & 217423 & 89016 & 136610 & 123957 & 4 \\
\hline 19 & Serviços industriais de utilidade pública & 511220 & 355483 & 91953 & 33415 & 30370 & 5 \\
\hline 4 & Siderurgia & 347247 & 193316 & 49029 & 37481 & 67421 & 6 \\
\hline 23 & Comunicações & 339162 & 203779 & 61767 & 41808 & 31808 & 7 \\
\hline 8 & Madeira e mobiliário & 331148 & 156642 & 50851 & 60777 & 62878 & 8 \\
\hline 3 & Minerais não-metálicos & 325524 & 171742 & 58763 & 41858 & 53160 & 9 \\
\hline 16 & Fabricação de calçados & 317450 & 195177 & 49710 & 39006 & 33557 & 10 \\
\hline 1 & Agropecuária & 308985 & 120179 & 56853 & 74676 & 57276 & 11 \\
\hline 5 & Máquinas e tratores & 308348 & 165562 & 37651 & 33147 & 71988 & 12 \\
\hline 21 & Comércio & 302388 & 127031 & 40184 & 72852 & 62322 & 13 \\
\hline 9 & Papel e gráfica & 282494 & 133474 & 52659 & 48026 & 48335 & 14 \\
\hline 11 & Química & 268633 & 149765 & 39398 & 36784 & 42686 & 15 \\
\hline 17 & Indústria de produtos alimentares, bebida e fumo & 265134 & 126974 & 42568 & 49430 & 46162 & 16 \\
\hline 6 & Material elétrico e equipamentos eletrônicos & 261790 & 167192 & 27024 & 31284 & 36290 & 17 \\
\hline 18 & Indústrias diversas & 261446 & 104782 & 43269 & 41655 & 71739 & 18 \\
\hline 14 & Indústria têxtil & 258634 & 122857 & 36709 & 53067 & 46000 & 19 \\
\hline 15 & Artigos do vestuário & 256075 & 97214 & 33628 & 70046 & 55187 & 20 \\
\hline 13 & Artigos de plástico & 251856 & 166946 & 30715 & 28614 & 25581 & 21 \\
\hline 20 & Construção civil & 243821 & 109252 & 40127 & 54250 & 40192 & 22 \\
\hline 2 & Extrativa mineral & 223601 & 108381 & 48248 & 29356 & 37617 & 23 \\
\hline 12 & Farmacêutica e perfumaria & 221085 & 124367 & 28014 & 37092 & 31613 & 24 \\
\hline 7 & Automóveis, caminhões e ônibus & 215982 & 147593 & 21256 & 24806 & 22327 & 25 \\
\hline 26 & Aluguel de imóveis & 198447 & 94577 & 32742 & 36569 & 34560 & 26 \\
\hline 10 & Indústria da borracha & 196645 & 127725 & 21578 & 25366 & 21976 & 27 \\
\hline
\end{tabular}

FONTES: Matriz de Contabilidade Social do Paraná, PNAD.

NOTA: Geração renda por R\$ 1 milhão. Cálculos do autor.

A Tabela 9 demonstra o resultado da aplicação da fórmula (3.7.1). A Administração Pública (27) continuou na primeira colocação, visto que é o Setor que possui a maior participação do salário no valor adicionado. Já a segunda colocação ficou para Aluguel de Imóveis (26). Nessa atividade, a característica da geração de renda é diferenciada das demais. Divide-se em três partes: aluguel imputado, aluguel pago e valor adicionado das empresas que fazem locação. A maior parte da composição é constituída por aluguel imputado, que é resultante do pagamento pelo uso do fator de produção terra, pois todo o fator de produção gera renda. Dessa forma, o imóvel residencial gera um aluguel imputado para o proprietário, gastando a renda na conta consumo das famílias, impulsionando o multiplicador de renda. As 
demais atividades relacionadas com o Setor Terciário também ficam entre as primeiras colocadas.

No que se refere à Indústria de Transformação, a Siderurgia (4), melhor colocada entre as indústrias que compõem a Indústria de Transformação, passou da 6. ${ }^{a}$ para $15 .{ }^{a}$ colocação. A atividade Minerais Não-Metálicos (3) passou para a 1. ${ }^{\mathrm{a}}$, impulsionada pela atividade da Construção Civil (20), a qual fornece insumos. A atividade Madeira e Mobiliário (8) e, principalmente, a atividade Papel e Gráfica (9) tiveram perdas na colocação quando comparadas com o multiplicador contábil de renda.

\section{Decomposição}

Os procedimentos metodológicos para a decomposição dos coeficientes de emprego são semelhantes aos da decomposição dos coeficientes de renda. Assim, não será detalhada esta questão.

Os resultados da decomposição estão na Tabela 10. Como se esperava, as atividades que compõem o Setor Terciário são as que têm os maiores multiplicadores de renda. Nesse Setor, a participação dos salários no valor adicionado é maior que no Setor Industrial. Por isso, não precisa de elevados investimentos para geração de renda, tal como no Setor Industrial. A atividade que tem o maior multiplicador de renda é Administração Pública (27). Esta não gera lucro. Sendo assim, seu valor total de renda gerada corresponde ao pagamento dos funcionários públicos, impulsionando o multiplicador. Em segundo lugar ficaram Instituições Financeiras (24), visto que, mesmo tendo na composição do seu valor bruto da produção o lucro, como os salários nessas atividades são mais elevados que nos demais setores, isso alavanca o seu multiplicador. 
NUÑEZ, B. E. C.; KURESKI, R.; PACHECO, C. H. P. Os multiplicadores de emprego e renda...

Tabela 9 - EFEITO RENDA NA GERAÇÃO DE RENDA, SEGUNDO A ATIVIDADE NO PARANÁ - 1998

\begin{tabular}{|c|c|c|c|c|c|c|c|}
\hline & \multirow[b]{2}{*}{ ATIVIDADE } & \multicolumn{5}{|c|}{ EFEITO RENDA (R\$) } & \multirow[b]{2}{*}{ POSIÇÃO } \\
\hline & & Total & $\begin{array}{c}\text { Empregado } \\
\text { com carteira }\end{array}$ & $\begin{array}{l}\text { Empregado } \\
\text { sem carteira }\end{array}$ & $\begin{array}{c}\text { Conta } \\
\text { própria }\end{array}$ & Empregador & \\
\hline 27 & Administração pública & 213.793 & 103.669 & 36.654 & 39.770 & 33.700 & 1 \\
\hline 24 & Instituições financeiras & 195.276 & 94.690 & 33.479 & 36.326 & 30.781 & 2 \\
\hline 26 & Aluguel de imóveis & 180.729 & 87.636 & 30.985 & 33.620 & 28.488 & 3 \\
\hline 25 & Serviços & 176.883 & 85.771 & 30.326 & 32.904 & 27.882 & 4 \\
\hline 22 & Transportes & 171.285 & 83.056 & 29.366 & 31.863 & 27.000 & 5 \\
\hline 1 & Agropecuária & 165.129 & 80.071 & 28.311 & 30.718 & 26.029 & 6 \\
\hline 19 & Serviços industriais de utilidade pública & 163.725 & 79.391 & 28.070 & 30.457 & 25.808 & 7 \\
\hline 23 & Comunicações & 155.412 & 75.360 & 26.645 & 28.910 & 24.498 & 8 \\
\hline 20 & Construção civil & 137.832 & 66.835 & 23.631 & 25.640 & 21.727 & 9 \\
\hline 3 & Minerais não-metálicos & 128.544 & 62.331 & 22.038 & 23.912 & 20.262 & 10 \\
\hline 11 & Química & 122.885 & 59.587 & 21.068 & 22.859 & 19.370 & 11 \\
\hline 8 & Madeira e mobiliário & 119.889 & 58.134 & 20.554 & 22.302 & 18.898 & 12 \\
\hline 17 & Indústria de produtos alimentares, bebida e fumo & 118.216 & 57.323 & 20.268 & 21.991 & 18.634 & 13 \\
\hline 5 & Máquina e tratores & 110.818 & 53.736 & 18.999 & 20.615 & 17.468 & 14 \\
\hline 4 & Siderurgia & 108.891 & 52.802 & 18.669 & 20.256 & 17.165 & 15 \\
\hline 21 & Comércio & 104.406 & 50.627 & 17.900 & 19.422 & 16.458 & 16 \\
\hline 14 & Indústria têxtil & 99.304 & 48.152 & 17.025 & 18.473 & 15.653 & 17 \\
\hline 16 & Fabricação de calçados & 96.612 & 46.847 & 16.564 & 17.972 & 15.229 & 18 \\
\hline 6 & Material elétrico e equipamentos eletrônicos & 96.151 & 46.624 & 16.485 & 17.886 & 15.156 & 19 \\
\hline 9 & Papel e gráfica & 94.074 & 45.617 & 16.129 & 17.500 & 14.829 & 20 \\
\hline 18 & Indústrias diversas & 92.966 & 45.079 & 15.939 & 17.294 & 14.654 & 21 \\
\hline 13 & Artigos de plástico & 91.917 & 44.571 & 15.759 & 17.099 & 14.489 & 22 \\
\hline 15 & Artigos do vestuário & 89.544 & 43.420 & 15.352 & 16.657 & 14.115 & 23 \\
\hline 12 & Farmacêutica e perfumaria & 86.434 & 41.912 & 14.819 & 16.079 & 13.625 & 24 \\
\hline 10 & Indústria da borracha & 80.994 & 39.274 & 13.886 & 15.067 & 12.767 & 25 \\
\hline 2 & Extrativa mineral & 79.936 & 38.761 & 13.705 & 14.870 & 12.600 & 26 \\
\hline 7 & Automóveis, caminhões e ônibus & 77.450 & 37.556 & 13.278 & 14.407 & 12.208 & 27 \\
\hline
\end{tabular}

FONTES: Matriz de Contabilidade Social do Paraná, PNAD.

NOTA: Geração por R\$ 1 milhão. Cálculos do autor.

A atividade Madeira e Mobiliário (8) ficou na oitava posição quando comparada com os totais das atividades, e em segundo lugar quando se trata somente de atividades da Indústria de Transformação. Para cada 1 milhão de reais gastos na demanda final gerava-se uma renda de 339.148 reais, sendo que 102.091 reais referem-se ao efeito direto, 109.198 reais são do efeito indireto e 119.889 reais do efeito-renda, em 1998.

A indústria de Papel e Gráfica (9) tem baixo coeficiente de renda direta - cerca de 23.343 reais para cada 1 milhão nos gastos finais - resultado da necessidade de altos investimentos em formação bruta de capital. O principal coeficiente de renda é o indireto, com 165.076 reais para cada 1 milhão nos gastos finais, por estar ligado a uma atividade com maior multiplicador de renda, como é o caso da Agropecuária. 
NUÑEZ, B. E. C.; KURESKI, R.; PACHECO, C. H. P. Os multiplicadores de emprego e renda...

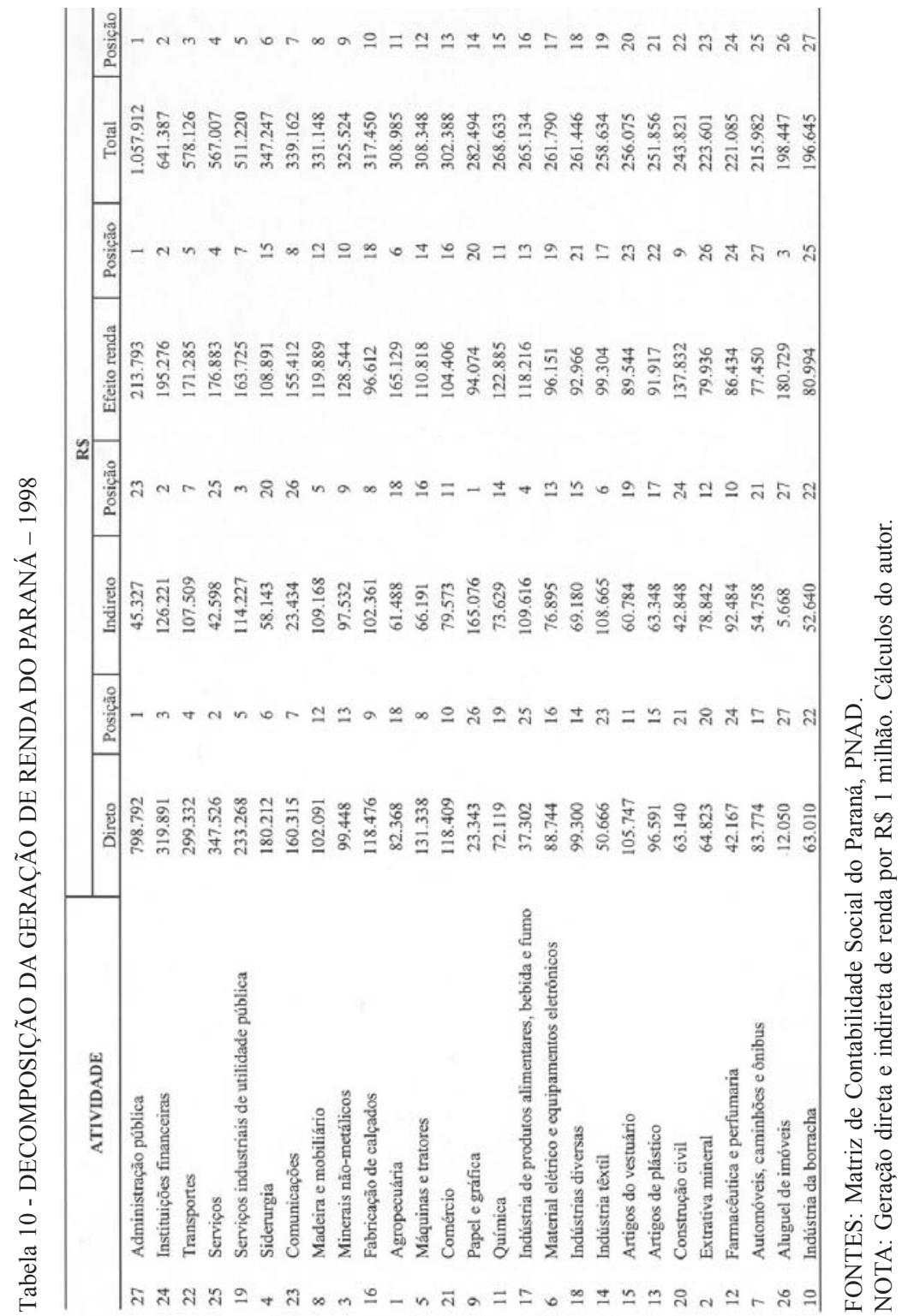




\section{CONSIDERAÇÕES FINAIS}

Neste artigo, determinaram-se os multiplicadores de emprego e renda direto, indireto e induzido da economia paranaense, dando ênfase para a indústria de Papel e Celulose e Madeira e Mobiliário. A fonte dos dados foi a matriz de contabilidade social do Paraná de 1998.

Para o cálculo dos multiplicadores, desagregou-se a conta de trabalho em quatro subcontas: empregado com carteira, empregado sem carteira, conta própria e empregador.

Para obter os multiplicadores de ocupação e renda, foram utilizados dados da Pesquisa Nacional de Amostra Domiciliar (Pnad) para obtenção do número de pessoas ocupadas no Paraná por atividade. Também utilizaram-se os dados para desagregação da conta dos salários em empregado com carteira, empregado sem carteira, conta própria e empregador. Contudo, os dados da Pnad e da Matriz de Contabilidade Social não estavam agregados de forma comparável. Com a compatibilização, resultou uma nova matriz de 39 x 39 atividades. Por meio da nova matriz, calcularam-se os multiplicadores de ocupação e renda do tipo I e II e o efeito renda.

A indústria de Papel e Gráfica e a de Madeira e Mobiliário foram classificadas na terceira e quarta posições, respectivamente, quanto ao multiplicador do tipo I, comparando-se ao conjunto de indústrias que compõem Indústria Extrativa Mineral e de Transformação. No primeiro caso, provavelmente o emprego vem puxado pelo setor gráfico, com predominância de empregados com carteira assinada. No segundo caso, a atividade teve quase $50 \%$ dos empregos gerados para trabalhadores sem carteira e por conta própria. O primeiro lugar é ocupado por Atividades de Artigos de Vestuário, por causa do grande número de trabalhadores autônomos.

Na questão da renda, a atividade Madeira e Mobiliário ficou na 8. ${ }^{a}$ colocação, superando a indústria de Papel e Gráfica, que ficou na 12. ${ }^{a}$ posição dentre todas as atividades. A diferença de posição é resultado da necessidade de acumulação maior por parte da indústria de Papel e Gráfica, em decorrência do maior dispêndio como investimento necessário para a produção de papel. Nesse caso, a 1. ${ }^{a}$ colocação ficou com a Administração Pública, em razão da característica da atividade, na qual todo o valor adicionado é considerado renda, não possuindo o excedente operacional bruto.

Também foi calculado o multiplicador de emprego do tipo II, que difere do primeiro multiplicador por incluir o efeito-renda. $\mathrm{O}$ que chamou atenção foi a diferença na grandeza dos resultados. O multiplicador de emprego do tipo II da Atividade Madeira e Mobiliário é superior 1,67 vez ao multiplicador do tipo I. 
Foi calculado o efeito-renda, ou seja, a diferença entre o multiplicador do tipo I e o multiplicador do tipo II. A atividade de Papel e Gráfica passou da 6. ${ }^{\mathrm{a}}$ para a 20. ${ }^{\mathrm{a}}$ posição, quando comparada com o multiplicador do emprego tipo I e com o multiplicador do tipo II, na classificação geral. Fazendo a mesma comparação para a Atividade Madeira e Mobiliário, esta passou da 9. ${ }^{a}$ para a 12. ${ }^{a}$ posição no ranking. A mudança não foi tão expressiva, por se tratar de uma atividade que engloba médias e pequenas empresas, que utilizam mais intensivamente mão-de-obra, resultando em uma relação entre a renda e o valor bruto da produção maior que a atividade de Papel e Gráfica.

Também a atividade Madeira e Mobiliário e, principalmente, a atividade Papel e Gráfica tiveram perdas na posição, quando comparadas com o multiplicador tipo II de renda.

O Instituto Brasileiro de Geografia e Estatística está utilizando novas pesquisas que substituíram os censos econômicos, tais como a Pesquisa Anual do Comércio e a Pesquisa Anual da Indústria, para construção de um novo ano-base para as contas nacionais. Este trabalho pretende fornecer informações referentes às atividades econômicas de forma mais desagregada. Fica como sugestão a utilização destas novas pesquisas para a construção de uma nova matriz de relações intersetoriais e de matriz de contabilidade social para o Estado do Paraná.

\section{RESUMO}

Este artigo apresenta os multiplicadores de emprego e renda direto, indireto e induzido da economia paranaense, dando ênfase para a indústria de papel e celulose e madeira e mobiliário. O primeiro passo para realização do trabalho foi a compatibilização das atividades da matriz de contabilidade social do Paraná com os dados da Pesquisa Nacional de Amostra Domiciliar (Pnad). Em seguida, foram obtidos os multiplicadores do tipo I, do tipo II e o efeito multiplicador induzido pela renda. Os resultados demonstram os efeitos de uma injeção nas variáveis exógenas dos demais setores sobre a indústria de Madeira e Mobiliário, e a de Papel e Papelão resulta em um choque mais intenso dentro do próprio setor. O multiplicadores de empregos para atividade de Papel e Gráfica e de Madeira e Mobiliário ficaram na décima e décima primeira posições, respectivamente, quando confrontados com as 27 atividades da matriz. Finalizando, com relação ao multiplicador de renda, a atividade de Madeira e Mobiliário ficou na oitava posição, quando comparada com os totais das atividades, e 
em segundo lugar, quando se trata somente de atividades da Indústria de Transformação.

Palavras-chave: multiplicadores; matriz de contabilidade social; indústria.

\begin{abstract}
The present article shows the direct, indirect and induced job and income multipliers of Paraná economy, highlighting Wood/Furniture and Pulp/Paper industries. For this work to be performed, the first step was to make the activities of the Paraná social accounting matrix be compatible with the Dwelling Sample National Research - PNAD. Next, we obtained type I and type II multipliers and the multiplier effect induced by income. The results show that the effect of injecting other sector exogenous variables into the Wood/Furniture and Pulp/ Paper industry produces a more intense shock within the sector itself. The job multipliers for the Paper/Printing and Wood/Furniture industries were ranked tenth and eleventh respectively, when compared to the matrix 27 activities. Finally, concerning the income multiplier, the Wood/Furniture industry was ranked eighth when compared with total activities, and second concerning the manufacturing industry activities.

Key-words: multipliers; social accounting matrix; industry.
\end{abstract}

\title{
REFERÊNCIAS
}

CABALlERO NUÑEZ, B. E.; C. H. P.; KURESKI, R. A matriz de contabilidade social do Paraná - 1998. [S.I.: s.n.], 2004.

CHAHAD, José P. Z. Estabilidade e desemprego em tempo de mudança: realidade e desafios no caso brasileiro. Indicadores Econômicos FEE, Porto Alegre, FEE, v. 26, n. 2, p. 170-193, out./dez. 1998.

FURTADO, Milton B. Síntese da economia brasileira. 7. ed. [S.1.]: LTC - Livro Técnico e Científico, 2000. 281p.

LACERDA, Antonio C. de et al. Economia brasileira. São Paulo: Saraiva, 2000. 262p.

LANZANA. Antonio E. T. O setor externo da economia brasileira. Manual de Economia

- Equipe de Professores da USP. 3. ed. - São Paulo: Saraiva 1998, p. 483-508.

NAJBERG, Sheila; IKEDA, Marcelo. Modelo de geração de emprego: metodologia e resultados. Rio de Janeiro: BNDES, 1999. 60p. 
NUÑEZ, B. E. C.; KURESKI, R.; PACHECO, C. H. P. Os multiplicadores de emprego e renda...

O’CONNOR, Robert; HENY, Edemundo D. W. Análise input-output e suas aplicações. Lisboa: Edições 70, 1975. 228p.

REIS, Carla; GIAMBIAGI, Fabio. Crescimento econômico e emprego no Brasil: o que podemos esperar. Conjuntura Econômica, Rio de Janeiro, FGV, v. 52, n. 5, p. 67-72, maio 1998.

THORBECKE, Erik. Social accounting matrices and social accounting analiysis. Methods of interregional and regional analysis. England: Ashgate, 1998.

Recebido em 21 jun. 2005 Aprovação final em 21 out. 2005 
NUÑEZ, B. E. C.; KURESKI, R.; PACHECO, C. H. P. Os multiplicadores de emprego e renda...

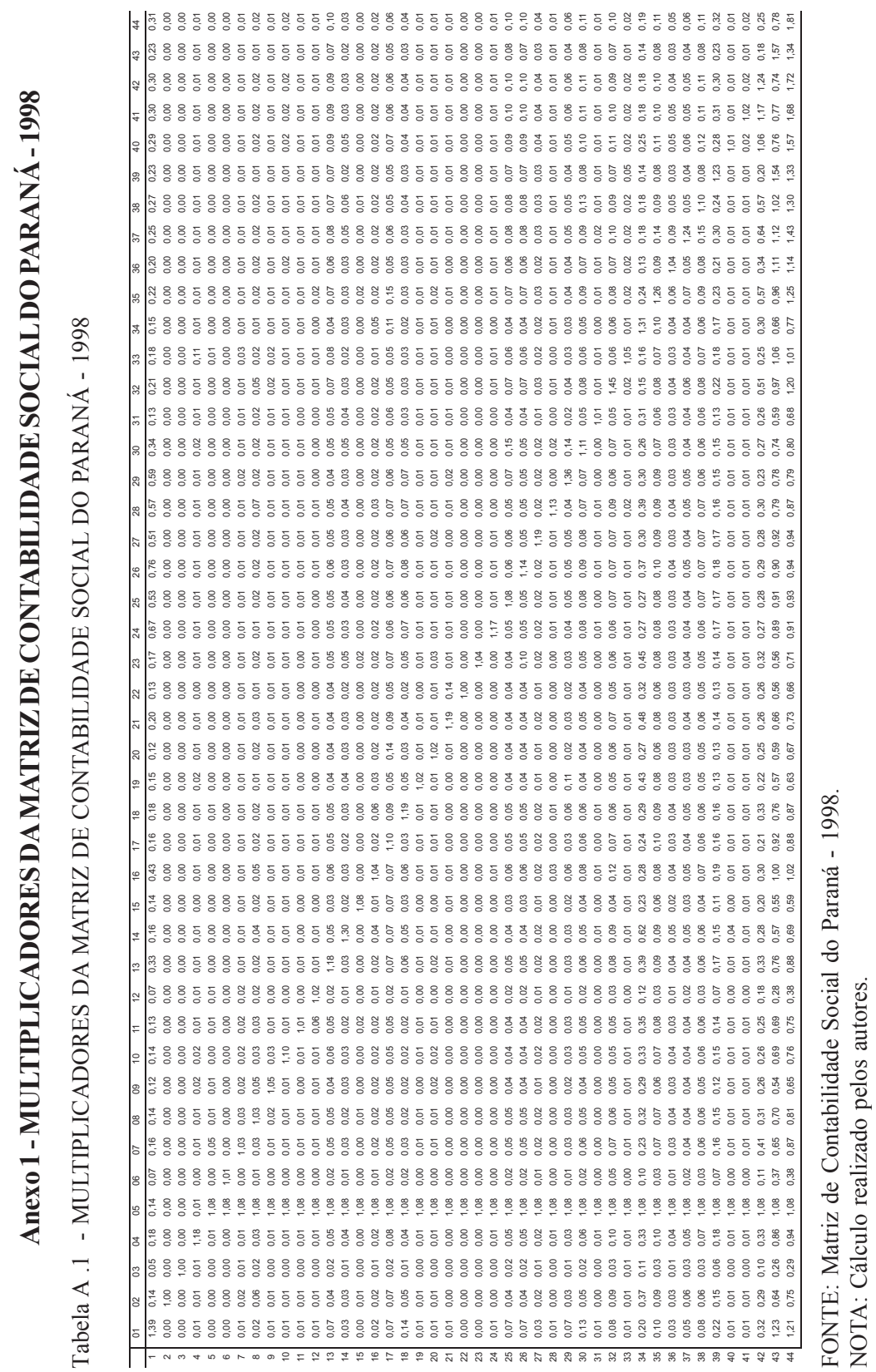

Economia, Curitiba, v.31, n. 2 (29), p. 73-111, jul./dez. 2005. Editora UFPR 
NUÑEZ, B. E. C.; KURESKI, R.; PACHECO, C. H. P. Os multiplicadores de emprego e renda...

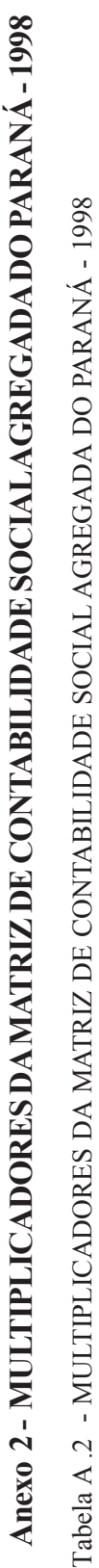

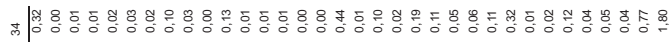

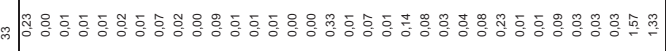

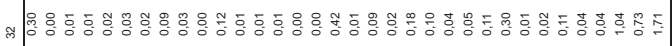

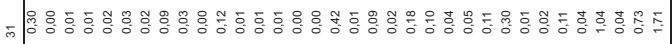

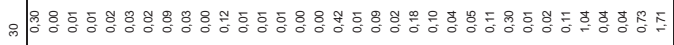

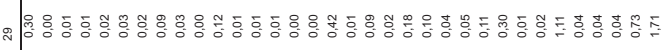

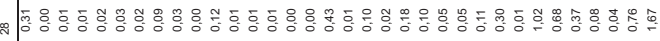

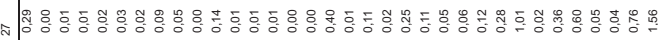

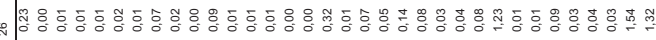

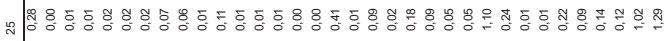

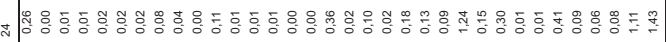

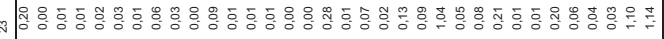

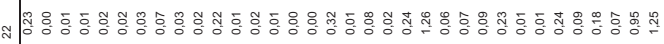

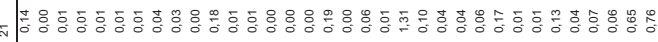
๙

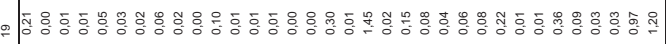

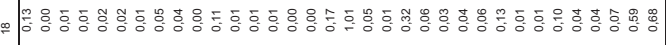

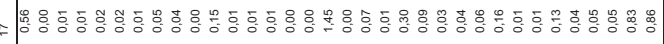

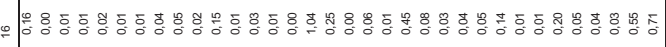

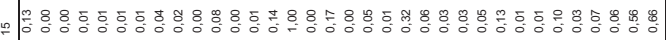

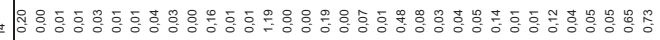

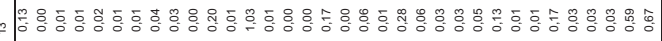

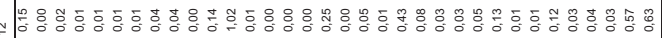

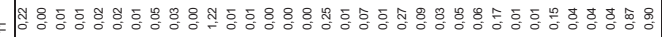

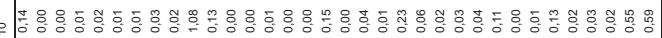

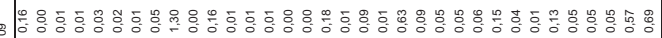

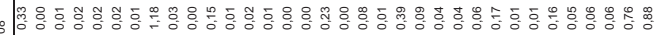

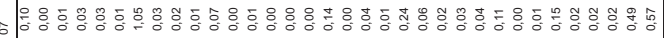

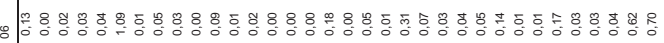

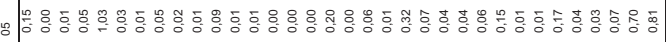

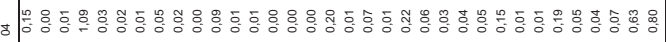

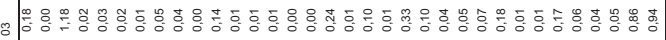

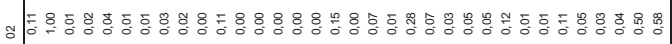

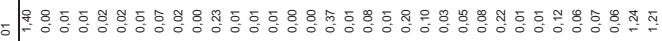




\section{Anexo 3 - COMPATIBILIZAÇÃO DAAGREGAÇÃO DAMCS (49 X49) PARA MSC (39X39)}

Quadro A.1- COMPATIBILIZAÇÃO DA AGREGAÇÃO DA MCS (49X49) PARA MSC (39X39)

\begin{tabular}{|c|c|c|c|}
\hline Código & Atividades & Código & Atividades agregadas \\
\hline 1 & Agropecuária & 1 & Agropecuária \\
\hline 2 & Extrativa Mineral & 2 & Extrativa Mineral \\
\hline 3 & Extração de petróleo e Gás & 3 & Minerais não-metálicos \\
\hline 4 & Minerais não-metálicos & & \\
\hline 5 & Siderurgia & 4 & Siderurgia \\
\hline 6 & Metalurgia Não-ferrosos & & \\
\hline 7 & Outros Metalúrgicos & & \\
\hline 8 & Máquinas e Tratores & 5 & Máquinas e Tratores \\
\hline 9 & Material Elétrico & 7 & Material Elétrico e Equipamentos Eletrônicos \\
\hline 10 & Equipamentos Eletrônicos & & \\
\hline 11 & Automóveis, Caminhões e Ônibus & 11 & Automóveis, Caminhões e Ônibus e Outros veículos e Peças \\
\hline 12 & Outros veículos e Peças & & \\
\hline 13 & Madeira e mobiliário & 8 & Madeira e mobiliário \\
\hline 14 & Papel e Gráfica & 9 & Papel e Gráfica \\
\hline 15 & Indústria da Borracha & 10 & Indústria da Borracha \\
\hline 16 & Química ñ petro.e Ref. Do Petróleo & 11 & Química \\
\hline 17 & Ref. de Petro.e indústria Petroq. & & \\
\hline 18 & Químicos Diversos & & \\
\hline 19 & Farmacêutica e Perfumaria & 12 & Farmacêutica e Perfumaria \\
\hline 20 & Artigos de Plástico & 13 & Artigos de Plástico \\
\hline 21 & Indústria Têxtil & 14 & Indústria Têxtil \\
\hline 22 & Artigos do Vestuário & 15 & Artigos do Vestuário \\
\hline 23 & Fabricação de Calçados & 16 & Fabricação de Calçados \\
\hline 24 & Indústria do Café & 17 & Indústria de produtos alimentares, bebida e fumo \\
\hline 25 & Benef. de Prod. Origem Vegetal & & \\
\hline 26 & Abate de Animais & & \\
\hline 27 & Indústria de Laticínios & & \\
\hline 28 & Indústria de Açúcar & & \\
\hline 29 & Fabricação de Óleos vegetasis & & \\
\hline 30 & Outro Produtos Alimentares & & \\
\hline 31 & Indústrias Diversas & 18 & Indústrias Diversas \\
\hline 32 & Serviços Indust.Utilid. Pública & 19 & Serviços Indust.Utilid. Pública \\
\hline 33 & Construção Civil & 20 & Construção Civil \\
\hline 34 & Comércio & 21 & Comércio \\
\hline 35 & Transportes & 22 & Transportes \\
\hline 36 & Comunicações & 23 & Comunicações \\
\hline 37 & Instituições Financeiras & 24 & Instituições Financeiras \\
\hline 38 & Serviços & 25 & Serviços \\
\hline 39 & Aluguel de Imóveis & 26 & Aluguel de Imóveis \\
\hline 40 & Administração Pública & 27 & Administração Pública \\
\hline 41 & Serv. Priv. não-mercantis & 28 & Serv. Priv. não-mercantis \\
\hline \multirow[t]{4}{*}{42} & trabalho & 29 & Empregado com carteira \\
\hline & & 30 & Empregado sem carteira \\
\hline & & 31 & Conta própria \\
\hline & & 32 & Empregador \\
\hline 43 & Capital & 33 & Capital \\
\hline 44 & Famílias & 34 & Famílias \\
\hline 45 & Tributos indiretos & 35 & Tributos indiretos \\
\hline 46 & Poupança & 36 & Poupança \\
\hline 47 & Importação Exterior & 37 & Importação Exterior \\
\hline 48 & Importação Resto do Brasil & 38 & Importação Resto do Brasil \\
\hline 49 & Oferta & 39 & Oferta \\
\hline
\end{tabular}

FONTE: Matriz de Contabilidade Social do Paraná - 1998.

NOTA: Agregação realizada pelos autores. 